\title{
A systematic review of the treatment and management of pre- eclampsia and eclampsia in Pakistan
}

Saleem Shaikh

Population Council

Ali M. Mir

Population Council

Follow this and additional works at: https://knowledgecommons.popcouncil.org/departments_sbsr-rh

Part of the Demography, Population, and Ecology Commons, Family, Life Course, and Society Commons, International Public Health Commons, Maternal and Child Health Commons, and the Medicine and Health Commons

How does access to this work benefit you? Let us know!

\section{Recommended Citation}

Shaikh, Saleem and Ali M. Mir. 2016. "A systematic review of the treatment and management of preeclampsia and eclampsia in Pakistan." Islamabad: Population Council. 


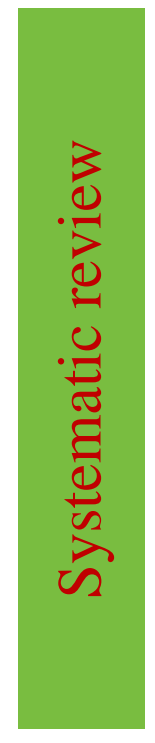

\section{ENDING Eclampsia}

A SYSTEMIATIC REVIEW OF THE TREATMENT AND MANAGEMENT OF PREECLAMPSIA AND ECLAMPSIA IN PAKISTAN

Saleem Shaikh Ali Muhammad Mir October, 2016 


\section{Introduction:}

Hypertensive disorders during pregnancy are important causes of severe morbidity, long-term disability, and death of both mothers and their babies. About 10 percent of the women experience increased blood pressure during pregnancy and less than 8 percent pregnancies get complicated by preeclampsia. Among the preeclampsia patients, about 10 percent develop severe preeclampsia and eclampsia. Globally, about 10-20 percent maternal deaths are associated with eclampsia ${ }^{1}$. The majority of deaths of mothers and their babies caused by severe preeclampsia and eclampsia (PE/E) are preventable through provision of timely and effective medical care. ${ }^{2}$

Pre-eclampsia is a multi-system disorder of unknown etiology characterized by development of hypertension to the extent of $140 / 90 \mathrm{mmHg}$ or more with proteinuria after $20^{\text {th }}$ week of gestation in a previously normotensive and non-protein uric pregnant woman. Pre-eclampsia has been associated with intrauterine growth retardation, preterm birth, maternal and perinatal death.

Globally, every day, more than 800 women, die from preventable complications related to pregnancy, childbirth and other causes, and 7,300 women experience a stillbirth (Lancet 2016). About 10 percent women experience hypertensive disorders during pregnancy (Duley et al 2009; Steegers et al 2010). Preeclampsia, defined as hypertension with proteinuria during pregnancy, complicates 4-5 percent of pregnancies (Steegers EA et al 2010; Abalos E et al 2013; Arulkumaran $\mathrm{N}$ et al 2013). In developing countries, a woman is seven times as likely as to develop preeclampsia than a woman in a developed country. From 10-25 percent of these cases will result in maternal death (WHO 2007).

\section{Pakistan Perspective}

\section{Magnitude of the Problem (Maternal morbidity and mortality trends)}

Pakistan is one of the six countries that account for more than $50 \%$ of the world's maternal deaths (Hogan et al. 2010). According to Population Council estimates, each year, nearly 8.6 million women become pregnant in the country. Of these, 15\%, i.e., 1.2 million women are likely to face obstetric complications (Sathar et al. 2013). Each year, there are nearly 14,000 pregnancy-related deaths (PRDs), which means on average one maternal death occurs every 40 minutes. Pakistan has also one of the highest neonatal mortality rates in the world at 55 per 100,000 live births. In KP, the NMR is 41 per 1,000 live births. 3

\footnotetext{
${ }^{1}$ World Health Organization (WHO) Make Every Mother and Child Count. The World Health Report 2005. Geneva: World Health Organization. ${ }^{2}$ World Health Organization WHO recommendations for prevention and treatment of pre-eclampsia and eclampsia. 2011, WHO. Geneva.

3 National Institute of Population Studies: Pakistan Demographic and Health Survey 2012-13. Report; $2013 . \quad$ URL: https://dhsprogram.com/pubs/pdf/FR290/FR290.pdf
} 
The maternal mortality ratio in Pakistan is estimated to be 276 per 100,000 live births. Although this number ranges from about 227 deaths per 100,000 live births in Punjab province to 789 deaths per 100,000 live births in Baluchistan province. Pakistan Demographic and Health Survey 2006-07 reported that amongst maternal deaths, eclampsia accounted for more than $12 \%$ of direct maternal deaths (PDHS 2006-07). ${ }^{4}$ More recently, Population Council carried out a provincial level study to estimate MMR of Punjab province by using a community based informants' network technique that is developed by the University of Aberdeen, UK. The study found that slightly more than a quarter of the deaths had occurred due to pregnancy-induced hypertension i.e. eclampsia (Population Council 2015). ${ }^{5}$

The last MMR estimate for the country was based on the Pakistan Demographic and Health Survey 2006-07 (NIPS 2008) that has not been since updated. The survey was able to provide provincially representative estimates of maternal mortality. The current estimates available are based on projections with very wide levels of uncertainty. For instance, the Global Burden of Diseases (GBD) estimates the 2014 MMR for Pakistan at 401 per 100,000 live births with uncertainty between 233 and $560 .^{5}$

\section{Initiatives taken by Pakistan}

The Government of Pakistan has, in recent years, initiated a number of major projects to improve maternal health outcomes in the country. Several important initiatives have also been launched to address the lack of maternal healthcare. However, updated maternal mortality estimates, especially at the provincial and district levels, are required to monitor and evaluate existing maternal, neonatal and child health $(\mathrm{MNCH})$ programs; to introduce greater accountability; and to plan new initiatives. Apart from updating numbers, it is also important from a programmatic perspective that the underlying causes of maternal mortality be well understood. This information will also help in advocacy efforts to increase awareness about maternal health issues among the public, and increase the focus of policymakers on this neglected area, thereby maintaining pressure towards achieving the new Sustainable Development Goals (SDGs) by 2030.

While the MMR is accepted as an important development indicator at the international and national levels, the range of simple, reliable and feasible methods for measuring maternal mortality is still limited, especially in developing countries. Maternal mortality is difficult to measure for a number of reasons. First, maternal death is a rare event and difficult to capture,

\footnotetext{
4 Pakistan Demographic and Health Survey 2006-07

5 Kassebaum NJ et al. Global, regional and national levels and causes of maternal mortality during 1990-2013: a systematic analysis for the Global Burden of Disease Study 2013. Lancet; 2014. 13; 384 (9947):980-1004.
}

(C) 2016 The Population Council, Inc. 
so large sample sizes are required for estimates to be reliable. For the same reason, measuring maternal mortality is also expensive. Secondly, at present there is no standard method that can be universally applied for measuring mortality; while various techniques have already been proposed or used to estimate maternal mortality in Pakistan, each has its limitations.

Ideally a vital registration system is the most accurate way of estimating maternal mortality, provided the system includes questions on cause of death and deaths are fully recorded. In Pakistan the vital registration system is still in the process of development and there is no provision for mandatory registration of deaths. Including mortality questions in the census questionnaire is a potentially comprehensive alternative method for measuring maternal deaths. However, this question has yet not been included in Pakistan, and would require considerable training of enumerators/interviewers to ensure a full count.

Many countries with deficient vital registration, including Pakistan, have used indirect techniques to generate maternal mortality estimates, such as conducting household surveysthe next best option to vital registration. However, to measure maternal mortality, household surveys must have a large sample size and they are therefore expensive undertakings, not easy to repeat regularly.

The indirect sisterhood method, which can be included in surveys with relatively smaller samples, uses reports by adults about aggregate numbers of surviving and deceased sisters, with additional questions related to the timing of death. This method identifies PRDs but tends to underestimate overall mortality because of inherent biases in data collection. More recently, direct sibling based methods have been introduced that provide all information required to estimate pregnancy-related mortality, including fertility, and also provide estimates of all female and male causes of mortality between the ages of 15 and 50 . However, they are at best able to produce national level estimates, since they generate large sampling errors.

Reproductive age mortality studies (RAMOS) were considered in the past as the gold standard for measuring maternal mortality. They involve systematic efforts to combine data on maternal deaths from multiple sources including vital registration, medical records, traditional birth attendants (TBAs), graveyard records, and verbal autopsies. RAMOS allow for important data collection on avoidable causes of deaths both at home and at the facility. However, these studies are complex, expensive, labor-intensive and largely applicable in settings with at least $60 \%$ completeness of reporting of adult female deaths in vital registration. Moreover, they do

(C) 2016 The Population Council, Inc. 
not provide a number of births for estimating the MMR and have rarely been carried out at a national level except in Egypt, Honduras and Guatemala.6,7

There is lack of information on context-specific health system barriers that prevent optimal use of the lifesaving medicine (magnesium sulfate) in Pakistan. Recent empirical evidence generated by a study, carried out in Pakistan, found that while international recommendations on MgSO4 have been adequately translated in national policies in Pakistan, the gap remains in implementation of national policies into practice. In Pakistan, although efforts both at the national and sub-national levels are ongoing on the prevention and treatment of $P E / E$, results are generally suboptimal and program interventions remain uncoordinated and fragmented. In several countries, poor procurement and distribution systems are responsible for low availability of the drug. In Pakistan, a study found that a fragmented system for registration, procurement and distribution was at the source of the low use of magnesium sulfate even though policies were all aligned with international standards (Bigdeli et al., 2013).

To fully appreciate the enormity of the problem at country level, we conducted a systematic review of published papers on PE/E in Pakistan from 2005-2015 in order to understand the key challenges, gaps and interventions related to the prevention and treatment of preeclampsia and eclampsia.

In recent years, the need for more precise sub- national estimates has increased. Post devolution after the 18th Constitutional Amendment, the provincial health departments are responsible for identifying priorities and developing provincial policies. Districts have also been empowered to develop their own health plans and seek the required allocation of resources from the district administration. The availability of reliable MMR estimates at both provincial and district level is essential for planning, monitoring, and evaluating maternal healthcare interventions.

\section{Material \& Methods:}

We searched PubMed; Google Scholar; Medline/POPLINE; Science Direct; Cochrane; World Health Organization Library Information System (WHOLIS) and all databases available through EBSCO Host of original articles published between January 2000 and June 2015.

\footnotetext{
${ }^{6}$ World Bank, Koblinsky M. Editor, Reducing Maternal Mortality. Learning from Bolivia, China, Egypt, Honduras, Indonesia, Jamaica, and Zimbabwe. Human Development Network, Health, Nutrition, and Population Series. The World Bank, Washington D.C. 2003

${ }^{7}$ Abouzahr C. Critical issues in safe motherhood, 110- 134, Geneva, WHO, 1999.
} 


\section{Inclusion criteria}

The overall selection criteria for this literature review were set in line with the study objectives of Landscape analysis on prevention and management of Preeclampsia/Eclampsia in Pakistan. Inclusion criteria of the literature include: studies published between 2000 and 2015, publication in English and peer reviewed and publications should have a focus on trials on preeclampsia, eclampsia, hypertension during pregnancy, use of loading dose of MgSO4 during SPE/E, the use of Aspirin prophylaxis for pregnant women at risk of developing PE/E, use of antihypertensive during pregnancy period, and use of loading dose of MgSO4 at the community/PHC level.

This systematic literature review was conducted in three phases to collect, organize and analyze the published literature on pre-eclampsia and eclampsia in Pakistan between 2000 and 2015.

\section{Exclusion Criteria}

Documents older than 2000 were not included in the review. Moreover documents which did not directly discuss the objective of the review were also excluded. In addition to this, some documents had too small sample size and some were not discussing PE/E in detail, these were also excluded.

\section{Phase I: Title \& abstract Screening}

During the phase one two independent reviewers conducted title and abstract screening to determine that abstracts should be included or excluded in the next phase of the review. Abstracts were excluded if they were: 1) Not about Pakistan, 2) Not related to pregnancy; (for example: abstracts about male subjects and abstracts that discussed hypertension but not in pregnancy were excluded) 3) Not related to $\mathrm{PE} / \mathrm{E}$ or associated risk factors, symptoms, or complications.

\section{PHASE II: Review of Complete Articles}

In the second phase, the two reviewers read the full text of the articles to determine their relevance and eliminated any papers that were based on data collected prior to 2000.

\section{PHASE III: Analysis}

Finally, the remaining articles were sorted into four types of papers-based on the main topic of each-that were found during the systematic review.

1. Descriptive Papers: case reviews, project reports, literature reviews etc.

2. Potential risk factors for pre-eclampsia and eclampsia

3. Other health outcomes associated with pre-eclampsia and eclampsia

4. Intervention: dosage or training/task-shifting 


\section{RESULTS}

After being screened as the most relevant documents 226 Abstracts were selected and reviewed. 11766 articles were excluded from the review. The detail is as under:-

A total of 11,766 searches were made in the following websites:-Pubmed, Cochrane, Science Direct, Popline and Wiley Online Library.

Google emerged with 85,900 searches of Eclampsia and 69, 100 searches of Pre-eclampsia in Pakistan. However it was not possible to peruse all documents thoroughly, therefore selected study was made of the most relevant documents.

The most relevant data was found in 226 reports of these websites.

Figure 1: Flow Diagram of Systematic Review Methods and Results

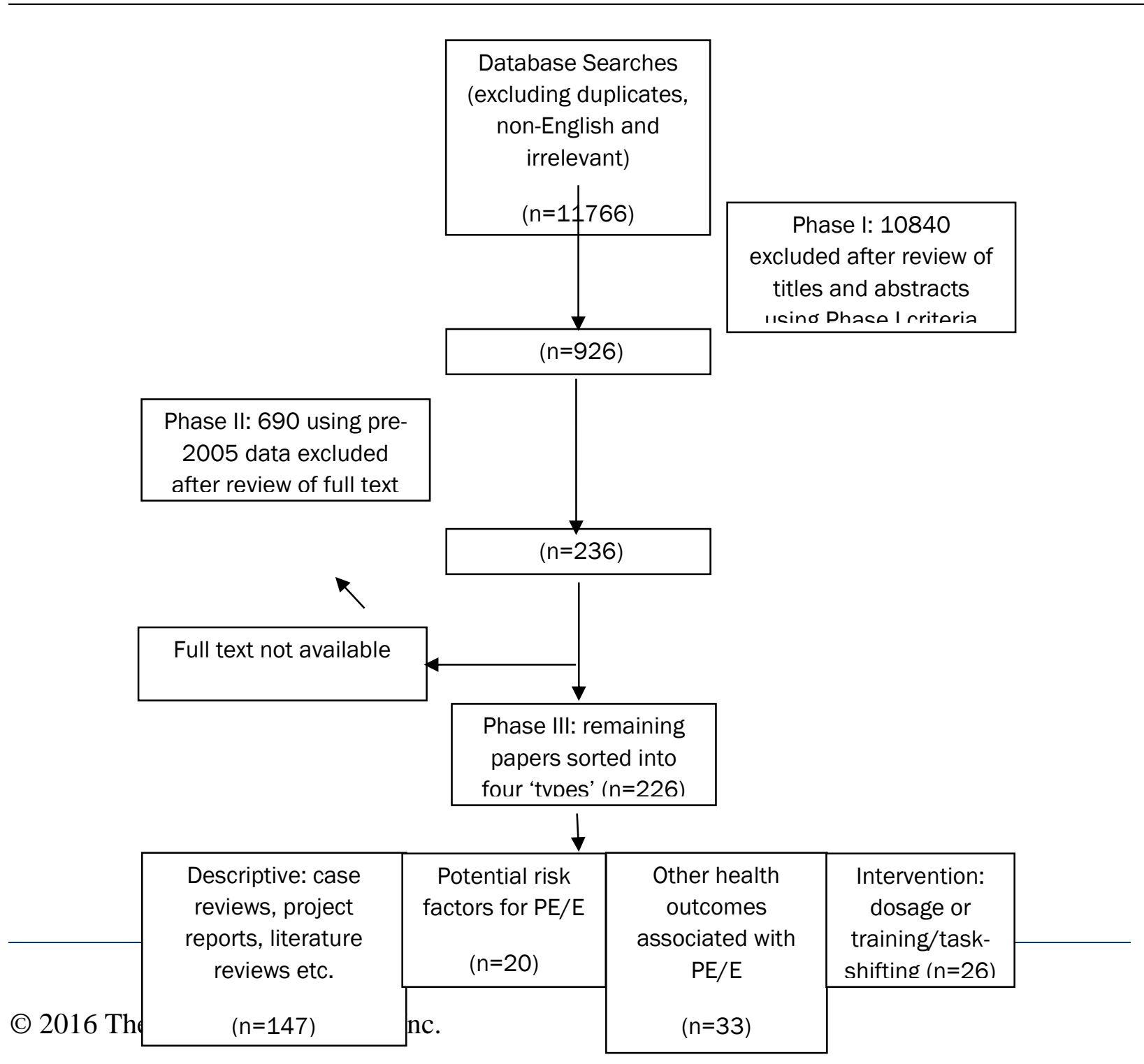




\section{Rating}

Rating of the documents was set as under:-

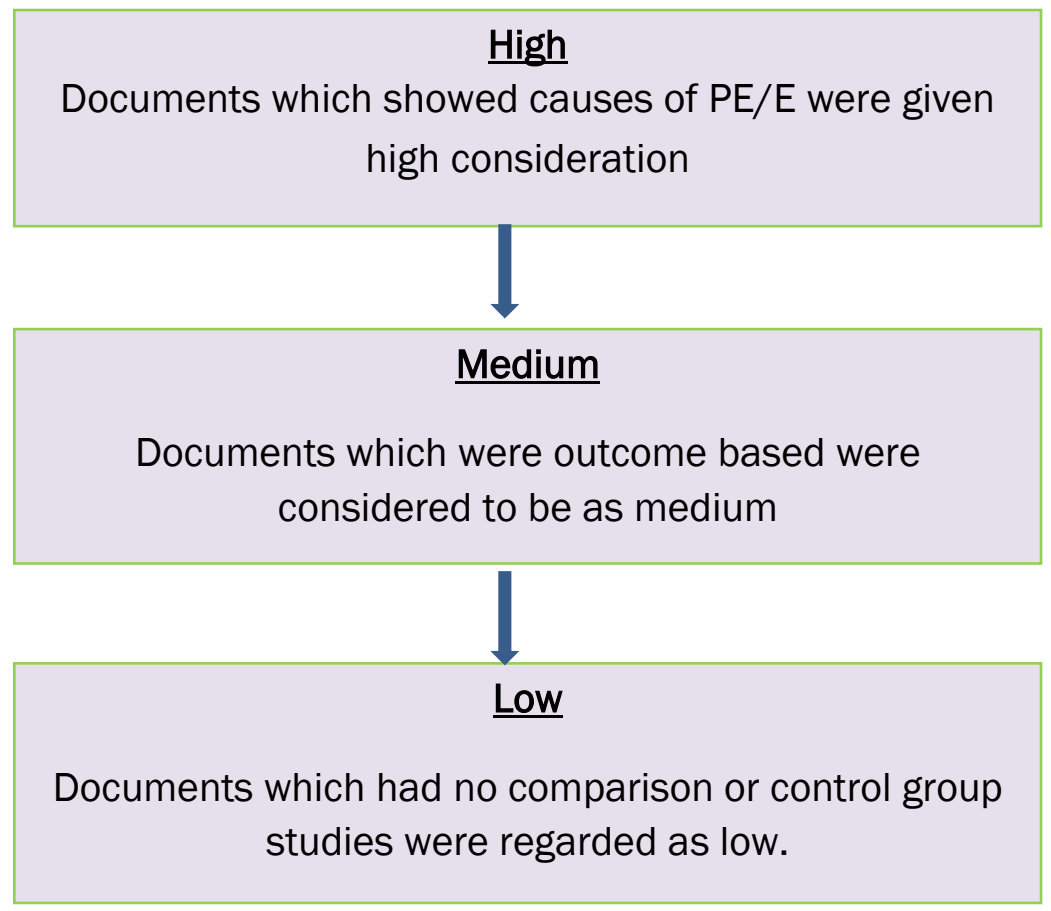

(C) 2016 The Population Council, Inc. 


\section{Risk Factors}

The reviewed literature highlights different risk factors for developing PE/E. According to three studies, pre-eclampsia occurs as a complication of pregnancy while Eclampsia occurs only as complication of Pre-eclampsia. Pre-eclampsia is most often seen in first pregnancy, teen age pregnancy or 40 years above pregnancy. It is a common pregnancy associated disorder especially in primigravida and teenagers [1, 2, 3]. Nulliparity, Multiparty/Multiple pregnancies and twin pregnancies also cause preeclampsia as per five other cross sectional research studies $[4,5,6,7,8]$.

According to Cross-sectional observational studies, pregnancy induced hypertension the leading risk factor for developing Pre-eclampsia is also found in metformin treated groups $[9,10]$. The frequency of presence of Breast Arterial Calcifications-BAC on mammography is also associated with systemic hypertension and higher age [11]. The risk for developing Pre-eclampsia was seen to be increased, with an interval of 10 years or more, from the previous pregnancy.

The assessment studies show that development of preeclampsia is associated with gestational diabetes pre-gestational diabetes, family history of hypertension, chronic hypertension, raised body mass index before pregnancy or at booking, mental stress during pregnancy, autoimmune disease, renal disease, fetal malformation and use of anti-depressive. Insulin dependent diabetes (IDDM) and Antiphospholipid syndrome also serve as risk factors for pre-eclampsia [12,13,14,15]. It also occurs due to food intake practices, food group consumption, and avoidance of any food, craving, aversion to any sort of food and/or non-consumption of adequate food [8]. Two more descriptive and prospective studies show that other risk factors leading towards pre-eclampsia are Doppler abnormalities \& biomarkers [14], Amniotic Fluid Index [16] and parity [17].

In addition to the above, lipid metabolism, increased triglycerides levels along with decreased HDLcholesterol levels and delayed triglycerides clearance are also associated with the development of preeclampsia [17]. Similarly, two facility based research studies show that raised levels of serum bilirubin and liver enzymes ALT, AST and ALK/HELLP Syndrome are a cause in women with Preeclampsia $[18,19]$.

Six cross sectional and case studies conducted at health facilities show that other than the medicinal ones, there are some other potential risk factors for developing PE/E. These are poverty [20, 21, 22, 23, 24, 25] illiteracy, low household income, unemployment, depressions, stress and gender inequality in Pakistan [26].

\section{Outcomes of PE/E}

Pakistan along with six other developing countries contributes to $50 \%$ of world's maternal deaths. Globally, maternal death occurs during childbirth in $11-17 \%$ cases while $50-71 \%$ deaths occur in the postpartum period. Majority of these deaths are avoidable [26].

Hypertensive disorders of pregnancy are a major cause of maternal and perinatal mortality and morbidity [25, 27,]. In Pakistan, its incidence and related mortality are high due to lack of adequate antenatal care and awareness. [28, 29, 30].

(C) 2016 The Population Council, Inc. 
There are severe and frequent pathological changes in preeclampsia and eclampsia cases [31]. The adverse effects of PE/E include edema, headache, seizure, and death [28, 32, 33, 34]. The other health outcomes of $\mathrm{PE} / \mathrm{E}$ include intrauterine growth restriction and still birth [35, 36, 37, 38, 39, 40, $41]$, congenital anomalies, haemorrhage [42, 43, 44], Breast Arterial Calcifications, fibrinoid necrosis \& hyalinization in placentae [45], morphology of placenta [46, 47] and Acute Kidney Injury-AKI [48]. Acute Kidney Injury-AKI is a frequently occurring complication in developing countries which ranges from 4\% to 36\%. In India and Pakistan, pregnancy-related AKI occurs mainly during the first trimester. These are related to severe states of sepsis. In Morocco, AKI occurs mainly in the third trimester in a context of hypertensive disorders. Total recovery of renal function depends on early and appropriate diagnosis and treatment. Prevention is the best strategy in this regard [48].

In addition to the above, in a number of cross-sectional studies it was estimated that pregnancy related Acute Renal Failure-ARF is the most common outcomes of PE/E and is a dangerous complication of pregnancy which carries very high mortality and morbidity [49, 50, 44, 51, 52, 53].

With regards to other outcomes of $\mathrm{PE} / \mathrm{E}$, there is a significant clinical correlation between pregnancyinduced hypertension, abruptio placentae $[54,55,56]$ and proteinuria [57]. (A patient's eight and/or 12-hour urine total protein values correlate with the 24-hour value to confirm the diagnosis of preeclampsia).

Exposure to PE/E also leads to raised Serum Bilirubin and Liver Enzymes/HELLP Syndrome [18], peripheral arterial disease [58], low APGAR score ${ }^{8}$, Intra-uterine Death, low birth weight and perinatal death $[59,60]$. Moreover, there are higher levels of serum leptin and higher levels of homocysteine in pregnancies complicated by pre-eclampsia and eclampsia [61].

In the same context, increased BMI [62], Renal, Cortical Necrosis [63] and elevated plasma leptin concentration appear to be a marker of pre-eclampsia independently or along with other parameters of pre-eclampsia [64]. In addition to these, loss of vision (Blurry vision and flashing lights, and floaters) are the other outcomes of eclampsia [65]. The literature also shows that there is strong association between preterm abruption and pre-eclampsia [66].

$\mathrm{PE} / \mathrm{E}$ ends up in delivery/pre-term delivery which is mainly Caesarian. A study was conducted in 2005 [67] in Peshawar Pakistan. The objective of this study was to determine the rate and clinical indications for emergency and elective caesarean section. The study shows that most of the caesarean sections were emergency caesarean sections. The rate of caesarean section was only slightly higher than recommended by the WHO (Naeem, 2015). Out of $22 \%$ caesarean sections $6 \%$ were due to pregnancy induced hypertension. Maternal morbidity in emergency versus elective caesarean section is significantly higher [68]. New-born resuscitation is required in such kind of high risk pregnancies and personnel trained in newborn resuscitation should be available at the time of delivery [69].

\footnotetext{
${ }^{8}$ Virginia Apgar invented the Apgar score in 1952 as a method to quickly summarize the health of newborn children through weight measurement after birth.
} 


\section{Evidences from Cases}

Malignant ovarian germ cell tumors at a tertiary care setting in Pakistan were studied [70] to see the frequency of placental infarcts in hypertensive preterm pregnancies and its effects on foetal outcomes (Hanan, 2015). Case records of 66 patients from 1994-2007 with MOGCT were reviewed. Findings highlight that histologically, dysgerminoma was the most common diagnosis followed by teratoma, yolk sac tumor, mixed germ cell tumor and embryonal carcinoma. The latter was found only in one patient. Median follow-up was 48 months. All patients underwent initial surgery. Fertility sparing procedures were performed in $75 \%$ patients. $58 \%$ patients achieved complete remission while $27 \%$ had progressive disease. $11 \%$ patients relapsed, all within first 3 years. Sixteen (88\%) of stage I while only 4 (26.6\%) of stage IV patients were alive at median follow-up (Hanan, 2015).

A case study conducted to assess maternal and perinatal outcome in nulliparious women complicated with pregnancy hypertension [71 shows that there were no significant differences in maternal age, menstruation condition, delivery mode, placental detachment rate between the studied groups. Gestational age was significantly lower in the case group, especially in severe preeclampsia subgroup. Serum creatinine level more than $1.2 \mathrm{mg} / \mathrm{dl}$ was significantly higher in mild and severe preeclampsia groups. Significant differences were found in neonatal APGAR, need of resuscitation, NICU admission, birth weight and length, LBW and intrauterine growth retardation between the studied groups.

\section{Detection}

The severity of PE/E can be avoided through early/timely detection of the disease. Correct diagnosis and timely intervention can decrease the risk of maternal and perinatal mortality owing to PE/E.

Factors like gestational diabetes, pre-gestational diabetes, family history of hypertension and mental stress during pregnancy can be used as a screening tool for pre-eclampsia prediction to timely diagnose and monitor women likely to develop preeclampsia before the onset of disease. This would facilitate timely interventions and ensure better maternal and fetal outcomes [1, 93].

PE can be predicted in primiparas in the early part of second trimester with serum levels of sFlt-19 and in the later part of second trimester with serum levels of Placental Growth Factor-PIGF10 [94]. As early diagnosis $[48,95,72,96]$ can lead to early treatment, it is utmost necessary to diagnose early for which routine antenatal check- up is a crucially important strategy.

In addition to the above, imaging also plays a primary role in the diagnosis of cerebral venous sinus thrombosis because the clinical picture of CVST is non-specific and highly variable [97]. Clinical presentation of the patient is most important in diagnosing viral encephalitis in postnatal women especially when patient presents with fever, altered sensorium and convulsions [98].

\footnotetext{
${ }^{9}$ Soluble fms-like tyrosine kinase-1 (sFlt-1 or sVEGFR-1) is a tyrosine kinase protein that disables proteins that cause blood vessel growth.

10 Placental growth factor
}

11 (C) 2016 The Population Council, Inc. 


\section{Management of Pre-eclampsia}

History

History of pre-eclampsia/eclampsia in previous pregnancy

$>$ History of pre-eclampsia/eclampsia in first degree relative

$>$ History of risk factors

\section{Examination}

$>$ Proper antenatal blood pressure record

$>$ Early recognition of pre-eclampsia which is often symptomless

$>$ Awareness of the serious nature if blood pressure is associated with proteinuria

Referral

$>$ Adherence to agreed guidelines for admission to hospital and investigations

Treatment

Agreed guidelines for the use of anti-hypertensive

$>$ Agreed guidelines for the use of anti-convulsants therapy where preference should be MgSO4

$>$ Delivery to prevent serious maternal and foetal complications

Follow-up

$>$ Postnatal follow-up

$>$ Appropriate contraceptive advice

During home deliveries, postpartum administration of $600 \mu \mathrm{g}$ oral misoprostol by trained TBAs $\mathrm{s}$ reduces the rate of PPH by 24\% [107]. This medicine is easy in use and is of low cost. Misoprostol can reduce $\mathrm{PPH}$ in community settings where the use of universal oxytocin prophylaxis is not feasible. With continuous training of TBAs on the use of Misoprostol with proper monitoring and evaluation system in place, maternal, perinatal and neonatal lives can be saved [106, 107].

Metformin is another effective and cheap treatment option for women with gestational diabetes with or without supplemental insulin $[108,109,110]$. During viral encephalitis in postnatal women who have convulsions, acyclovir therapy should immediately be started while making other investigations [98]. Moreover, peritoneal closure is beneficial in routine caesarean sections [111].

Vitamin D supplementation in pregnancy can also improve maternal and neonatal outcomes [112]. Improvement in the management of hypertension and diagnosis of congenital anomalies [113] and improvement in maternity care services [114] is necessary to reduce still birth.

With advancing pregnancy, intraocular pressure decreases. The mean intraocular pressures of third trimester hypertensive pregnant women are significantly higher from that of third trimester nonhypertensive mothers. Therefore knowledge of Providers on the normal level of intraocular pressure in various stages of pregnancy may help glaucoma screeners [115]. 
$\mathrm{MgSO}_{4}$ should be made available throughout the year in the provinces. Moreover prefilled standard dose should be purchased and prefilled dosage preparation should be available with the Providers [122]. Injections should be ready to use with no preparation required.

There should be multiple suppliers of $\mathrm{MgSO}_{4}$. Its use should be enhanced by rewarding those who are using it. Moreover, advocacy should be made for the accessibility and use of magnesium sulfate in the country.

\section{Treatment}

Magnesium Sulphate $\left(\mathrm{MgSO}_{4}\right)$ is the best way to treat PE/E than other anti-convulsants. Initial loading dose of magnesium sulphate not only prevents but also treats Eclampsia. $\mathrm{MgSO}_{4}$ is low-cost. Moreover subsequent follow up of $\mathrm{MgSO}_{4}$ is also easier. Therefore, $\mathrm{MgSO}_{4}$ is appropriate for use by $\mathrm{PHC}$ Providers. However, the dosage and duration of $\mathrm{MgSO}_{4}$ therapy should be decided after keeping in mind the local context [99].

$\mathrm{MgSO}_{4}$ acts as a vasodilator, with actions in the peripheral vasculature or the cerebrovasculature. It decreases peripheral vascular resistance and also relieves vasoconstriction. Moreover, $\mathrm{MgSO}_{4}$ also protects the blood-brain barrier and limits cerebral edema formation. It also acts through a central anticonvulsant action [100]. Use of MgSO4 is as under [101]:-

\section{Dosage of $\mathrm{MgSO}_{4} \mathrm{I} / \mathrm{M}$ loading dose}

10 gms (10 ml or 01 ampule) of $\mathrm{MgSO}_{4}$ Injection given as a loading dose (5gms in each 4 buttock I/M) and dilute this with $10 \mathrm{ml}$ of normal saline and $2 \%$ xylocaine injection i.e. total of $10 \mathrm{gms}$ [101].

\section{Loading Dose of $\mathrm{MgSO}_{4}$}

$>$ A loading dose of $4 \mathrm{gms}\left(8 \mathrm{ml}\right.$ of $10 \mathrm{ml}$ vial) of $\mathrm{MgSO}_{4}$ in $50 \mathrm{ml}$ of solution over 10 minutes 4 by an intravenous infusion.

$>$ Followed by $\mathrm{l} / \mathrm{M}$ Injection of $5 \mathrm{gms}\left(10 \mathrm{ml}\right.$ or 1 vial) of $\mathrm{MgSO}_{4}$ mixed with $1 \mathrm{ml}$ of $2 \%$ lignocaine injection first in one buttock and then the other making a total of $14 \mathrm{gms}$.

Maintenance dose of $\mathrm{MgSO}_{4}$

$>$ Maintenance dose of 5 gms (10 ml or 1 vial) of $\mathrm{MgSO}_{4}$ mixed with $2 \%$ lignocaine $1 \mathrm{ml}$ is 4 then is given 4 hourly $\mathrm{l} / \mathrm{M}$ in alternate buttock for 24 hours (Pritchard regimen) after delivery.

If seizures continue or recur:-

$>\mathrm{MgSO}_{4} 2 \mathrm{~g} \mathrm{l} / \mathrm{V}$ can be repeated when required. If this fails then diazepam $10 \mathrm{ml} \mathrm{I} / \mathrm{V}$ or 4 thiopentone $50 \mathrm{mg} \mathrm{l} / \mathrm{V}$.

Monitoring of $\mathrm{MgSO}_{4}$ therapy

$>$ Once $\mathrm{MgSO}_{4}$ is given monitoring of the patient should be done every 10 minutes for first 42 hours and then every 30 minutes by:-

- Urine output (more than $25 \mathrm{mls} /$ hour

13 (C) 2016 The Population Council, Inc. 
- Knee jerk (should be present)

- Respiratory rate (more than 16/ min)

If either of these is disturbed $\mathrm{MgSO}_{4}$ should be stopped immediately. Antidote is Calcium Gluconate Injection $10 \mathrm{ml}$ is given slowly I/V over 10 minutes [101].

Magnesium Sulphate- $\mathrm{MgSO}_{4}$ is registered in Pakistan as the first line treatment of eclampsia and severe eclampsia. The medicine is also enlisted in National Essential Medicines List, Pakistan National Formulary and MNCH EmONC Training Manual [102].

There are certain clinical requirements for the use of magnesium sulfate, which include the availability of infusion pumps for I/V use, dosage preparation, availability of the antidote calcium gluconate and understanding the contra-indication to use especially alongside diazepam. Magnesium levels are not required routinely for its use. This clearly demonstrates that along with the formulation of clinical guidelines, procedures need to be in place at facility level with relevant staff trained and equipment available [102].

\section{Pakistan Perspective}

In Pakistan, 10 grams (10 $\mathrm{ml}$ or 01 ampule) of MgSO Injection is given as a loading dose (5gms in each 4 buttock $\mathrm{I} / \mathrm{M}$ ) and this is diluted with $10 \mathrm{ml}$ of normal saline and $2 \%$ xylocaine injection i.e. total of 10 grams is given.

\section{Loading Dose of MgSO4}

A loading dose of $4 \mathrm{gms}(8 \mathrm{ml}$ of $10 \mathrm{ml}$ vial) of $\mathrm{MgSO}$ in $50 \mathrm{ml}$ of solution over 10 minutes 4

$>$ by an intravenous infusion

$>$ Followed by $\mathrm{I} / \mathrm{M}$ Injection of $5 \mathrm{gms}$ (10 $\mathrm{ml}$ or 1 vial) of $\mathrm{MgSO} 4$ mixed with $1 \mathrm{ml}$ of $2 \%$

$>$ lignocaine injection first in one buttock and then the other making a total of $14 \mathrm{gms}$.

\section{Maintenance dose of MgSO4}

> Maintenance dose of 5 gms (10 $\mathrm{ml}$ or 1 vial) of MgSO mixed with $2 \%$ lignocaine $1 \mathrm{ml}$ is $>$ then given 4 hourly $\mathrm{l} / \mathrm{M}$ in alternate buttock for 24 hours (Pritchard regimen) after

$>$ delivery.

\section{If seizures continue or recur}

$>$ MgSO $2 \mathrm{~g} \mathrm{I} / \mathrm{V}$ can be repeated when required. If this fails then diazepam $10 \mathrm{ml} \mathrm{I} / \mathrm{V}$ or 4 thiopentone $50 \mathrm{mg} \mathrm{l} / \mathrm{V}$

\section{Monitoring of MgSO therapy 4}

$>$ Once MgSO is given monitoring of the patient should be done every 10 minutes for first 2 hours and then every 30 minutes by:

14 (C) 2016 The Population Council, Inc. 
- Urine output (more than $25 \mathrm{mls} /$ hour)

- Knee jerk (should be present)

- Respiratory rate (more than $16 / \mathrm{min}$ )

If either of these is disturbed MgSO should be stopped immediately.

Antidote is Calcium Gluconate Injection $10 \mathrm{ml}$ given slowly I/V over 10 minutes.

\section{Challenges in the use of MgSO4:}

While international recommendations on $\mathrm{MgSO}_{4}$ have been adequately translated in national policies in Pakistan, gap remains in the implementation of national policies into practice. Barriers to access to and effective use of $\mathrm{MgSO}_{4}$ occur at health facility level where the medicine is not available and health staff is reluctant to use it. Low price of the medicine and the small market related to its narrow indications also act as disincentives for the effective marketing of $\mathrm{MgSO}_{4}$ [118]. Due to these reasons like in many other Low- and Middle-Income Countries, $\mathrm{MgSO}_{4}$ is enormously under-utilized in Pakistan. There are context-specific health system barriers that prevent optimal use of this life-saving medicine, which should be removed to enhance the use of $\mathrm{MgSO}_{4}$ [119].

Supply of $\mathrm{MgSO}_{4}$ is interrupted sometimes and provinces face shortage of the same. The preparation of its dosage is also difficult. Moreover there are misconceptions about its use among the senior Obstetricians.

Other than medicinal one, to balance the timing of delivery of patients with pre-eclampsia before the onset of eclampsia is also a major challenge [120].

Magnesium sulfate is on WHO's essential medicines list since 1996 and since 2003 which has specifically been included for the treatment of severe pre-eclampsia and eclampsia. If $\mathrm{MgSO}_{4}$ is used appropriately in Pakistan it can bring about a significant reduction in the maternal mortality and morbidity rates $[121,122]$.

\section{Strategies to reduce $\mathrm{PE} / \mathrm{E}$}

Short term, medium term and longer term Strategies need to be developed based on competencybased training and deployment and supervision of a cadre of skilled attendants for delivery at the community level. In addition upgrading of health care systems especially availability of emergency obstetric care is urgently required to overcome PE/E and maternal mortality related with it [123]. Thus continued efforts are needed to improve the availability and quality of Emergency Obstetric and Newborn Care through targeted skill-based training [124, 125] and provision of adequate drugs and equipment [124, 126]. There should be proper legislation for this [125].

Maternal morbidity and mortality can be reduced through safe motherhood programs, provision of separate ICU services for critically ill obstetrical patients and early assessment \& intervention through a team work approach involving obstetricians, Intensivists and Anesthetists [127]. Delivery of proper health care system and emergency obstetrical care facilities are vital for the early detection and proper management of PE/E. Provision of skilled care and timely management of complications can reduce 
maternal mortality in our country [84]. With proper peripartum care, [128], complete utilization of medical treatment [70] and close monitoring in post-operative period [129] maternal mortality can be reduced.

Long-term mobilization of social structure and governance is also needed to encourage maternal health awareness, hospital deliveries, and formal sector employment for employed mothers [130].

Providing balanced protein energy and multiple micronutrient supplements to pregnant women will reduce incidence of Intrauterine Growth Restriction -IUGR. Moreover, community-based intervention packages are among the most effective methods of reducing morbidity and mortality in mothers and children [131, 132]. Maternal and newborn care programs should be integrated in community settings through community health workers, self-help groups and health promotion groups. Community-based care should be scaled up through packages to be delivered by community-based workers [132]. Micronutrient malnutrition programs should be integrated in maternal, nutrition and antenatal care programs to maximize outcome [77]. Poverty alleviation and nutritional support programs can be launched for women of reproductive age and all these can also be packaged in the $\mathrm{MNCH}$ program [24].

Linkage of $\mathrm{RHMNCH}$ with other health and nutrition programs will bring effective results under maternal and newborn health and save from duplication of efforts and resources in interventions related to PE/E [133]. This will also enhance the efficiency of training, monitoring, and supervision of health care workers dealing with PE/E; it will also help families and communities to access and use health care services providing PE/E treatment easily [133]. Log books to document skill use during emergency obstetric care can be launched and used to measure outcome of PE/E programs and monitor the performance of health care workers and providers [134].

The literature depicts that sustained investment in health care reforms [135], political will and partnerships to implement evidence-based PE/E interventions at scale [136], skilled care at facility level and household care at community level for improving maternal, newborn and child survival [137] are the best strategies to reduce PE/E in specific and maternal mortality as a whole.

In addition to the above, it is crucially important to increase the accessibility of ANC services by extending facility working hours and making adjustments according to the convenience of clients in primary healthcare (PHC) facilities. The utilization of ANC services can also be enhanced through community awareness and gender empowerment for ANC decision making [72, 138,].

Depression is the leading cause of hypertension. To cope with depression during pregnancy, Gynaechologists and Psychiatrists should work together in managing such patients [4] so that it does not lead to hypertension. 


\section{Laboratory Services}

Elevated plasma leptin concentration appears to be a marker of pre-eclampsia independently or along with other parameters of pre-eclampsia. This can be used to reduce the severity of pre-eclampsia thus avoiding risk effects of pre-eclampsia to mother and foetus [116]. In addition to this, management and delivery of HELLP syndrome patients can be performed at tertiary care centres, where highly trained obstetrician, neonatal intensive care unit personnel and Multi-disciplinary facilities are available [117].

\section{Community- based Prevention}

$\mathrm{PE} / \mathrm{E}$ can be prevented through routine antenatal examination, availability of health facilities at an ease of access and prompt referral to tertiary care hospital [5, 70, 71, 72]. In order to decrease the adverse outcome of eclampsia a community-based approach is needed to improve community health education, socioeconomic status and prenatal care [73]. In addition to this, delivery of proper health care system and emergency obstetrical care facilities are vital for the prevention of PE/E [73]. Maternal mortality can be reduced with proper peripartum care [29] and skilled care during pregnancy, childbirth, and postnatal period [74]. Assessment of blood lipids is also helpful in the prevention of complications in patients with pregnancy-induced hypertension.

Vitamin -D deficiency and Pre-eclampsia are correlated, therefore, PE can be prevented by overcoming this deficiency and other micronutrient malnutrition [75, 76] like iron and folic acid [77]. Likewise calcium supplementation during pregnancy is associated with reduction in risk of gestational hypertensive disorders, pre-term birth and an increase in birth weight which can also be looked into for interventions aiming to prevent PE/E [78, 79, 80, 81]. However further research is needed to assess its benefit in detail [82].

In addition to this the creation of increased community demand for health services and increasing their uptake also can play a role in preventing PE/E and its outcomes including stillbirths [83]. Other potential socio-behavioral interventions include birth spacing, smoking cessation and indoor air pollution control, although the evidence for these is weak in the literature [83]. Mitigation of all risk factors identified for still birth and periodontal disease can prevent the outcome of PE/E. Infection control measures, syphilis screening \& treatment and malaria prophylaxis in endemic areas are strong interventions for preventing antepartum still births. As still birth is preventable with high quality obstetric care, $[84,85]$ related interventions should be incorporated into antenatal care programs [86]. Basic and Comprehensive Emergency Obstetric Care are the effective interventions to reduce intrapartum stillbirths though a lot more needs to be done in this regard [87]. 


\section{Facility - based Prevention}

PE/E can also be prevented through facility level interventions. Up-gradation of health facilities including tertiary level hospitals and deployment of senior, skilled and experienced personnel in the management of obstetrics emergencies can effectively reduce caesarean section rate and maternal morbidity \& mortality. This would ultimately improve fetal outcome as well [48]. Moreover, community sensitization for early antenatal booking and provision of emergency obstetric care services at door step will also improve obstetric outcome [88].

\section{Importance of Public Health initiatives}

Importance of public health interventions for preventing PE/E can also not be denied. Improving education, nutrition, and uniform implementation of obstetric care protocols are needed for better maternal and neonatal health in Pakistan [89]. Focus of attention should be there on regular ANC and follow up, Vitamin-A Supplementation and Calcium Supplementation, strengthened Referral to tertiary care hospitals and strengthening of the four interlinked health system elements i.e. human resources, access to, use and quality of services is essential though not sufficient strategies for the prevention of PE/E [90, 91].

Improving education, nutrition, and uniform implementation of obstetric care protocols are needed for better maternal and neonatal health in Pakistan [92]. Gender empowerment, decision making and provision of adequate drugs \& equipment at health facilities are the best strategies to prevent or reduce $\mathrm{PE} / \mathrm{E}$.

\section{Procurement and Distribution:}

The medicine is procured by Ministry of National Health Services Regulation and Coordination. There is no budget allocated to the provinces whereas the medicine is directly procured by the provinces. Acquisition, storage and distribution of $\mathrm{MgSO}_{4}$ is done by Provincial Medical Store Depot who then supplies $\mathrm{MgSO}_{4}$ to Government hospital pharmacies and District Health Offices. Private hospitals buy $\mathrm{MgSO}_{4}$ from the open market. Grant is also given to specialized hospitals like Pakistan Institute of Medical Sciences to procure emergency medicines including $\mathrm{MgSO}_{4}$ independently. Procurement of this medicine depends on the demand of health department [102].

Other than $\mathrm{MgSO}_{4}$, use of low dose aspirin and low molecular weight heparin is safe in pregnancy and it improves foetal outcome in patients with recurrent pregnancy loss due to anti-phospholipids syndrome [103, 104, 105]. 


\section{Demand and Supply}

\section{Demand}

According to a study conducted in 2010 (Hafeez, 2010) training and intervention was found to be extremely facilitative factor for the use of $\mathrm{MG} \mathrm{SO}_{4}$ even in the non-teaching facilities. Most of the doctors found the dosage preparation to be the biggest barrier to the use of the medicine as they had to recall, calculate and prepare the dosage themselves [102].

Due to lack of training and non-inclusion of the use of MgSO4 in in-service training, there is lack of demand in health care providers with regards to MgSO4. Lack of community awareness is also another factor behind the low demand generation of the medicine.

\section{Supply}

Lack of demand is contributing to lack of supply. Before initiating any intervention to improve the management of eclampsia and severe eclampsia Pakistan a thorough understanding of the local context needs to be made. Pakistan is facing constraints in the utilization of $\mathrm{MgSO}_{4}$ due to lack of clinical guidelines, difficult dosage calculation of the medicine and lack of equipment, human resources and trainings. [102]

MgSO4 needs to be made available to provinces throughout the year by having multiple suppliers. Moreover prefilled standard dose needs to be purchased to maximize its correct use.

\section{Health System Barriers in the use of MgSO4 in Pakistan}

Lack of procurement, lack of availability and inadequate and improper use of MgSO4 is the greatest barrier in the use of this medicine in Pakistan. Other common barriers are complex dosing regimens, a lack of product harmonization, low familiarity of the drug, and hesitation of health care providers to administer MgSO4 due to its perceived side effects, all of which limit its impact. Yet another barrier is delay in the administration of second dose in case of referral.

Other than the above, lack of training is adversely affecting the treatment of PE/E. according to a study conducted in 2010 (Hafeez, 2010) some of the teaching hospitals were found to be using diazepam and $\mathrm{MgSO}_{4}$ together for admitted eclampsia patients. This was against the standard treatment guidelines and it was dangerous to use this medicine in such a way. Some of the staff working in the non-teaching settings had received EmNOC trainings by $\mathrm{MNCH}$ program which had enhanced their awareness on the use of $\mathrm{MgSO}_{4}$. However, the lower level hospitals providing maternal care were better equipped and were using $\mathrm{MgSO}_{4}$ injections for eclampsia.

\section{Community Review/Case Studies}

A Study Frequency and Impact of Hypertensive Disorders of Pregnancy [27] conducted in 2014 (Parveen M. Aabidha, 2015) shows that total deliveries during study period were 2702. Out of 2702 deliveries 150 (5.5\%) mothers were hypertensive. Out of 150 hypertensive cases 30\% were cases of gestational hypertension, $58 \%$ were cases of toxemia of pregnancy and $12 \%$ were cases of 
chronic hypertension. Maternal age, gravida, parity was lowest in toxemia of pregnancy group. Commonest maternal complication was eclampsia (32\%). There were 6 (4\%) maternal deaths. Caesarean section was mode of delivery in $54 \%$ cases. Thus, hypertension disorders of pregnancy appear to be an important cause of maternal and perinatal mortality and morbidity (Parveen M. Aabidha, 2015).

According to another case study [105] (Sultana, 2005) a total of 2100 admissions were made in the labor ward during this period and out of them 68 cases (3.23\%) were of eclampsia. Out of them 28 were primigravida, 14 multigravida and 26 grandmultigravidae. The seasonal frequency of cases was $29.41 \%$ in winters, $42.64 \%$ in autumn, $19.11 \%$ in summers and $8.82 \%$ in spring. Out of these $11.76 \%$ cases were complicated with retro placental hemorrhage and the same number with aspiration pneumonia, while Cerebrovascular Accident (2.94\%) Acute tubular necrosis (2.94\%) and Disseminated intravascular clotting (4.4\%) were also seen. Among the newborns prematurity was found to be the major cause of perinatal mortality. Eclampsia is a dreadful complication of Pre eclamptic Toxemia of pregnancy associated with high perinatal and maternal mortality. A qualitative and quantitative improvement in prenatal consultation should make it possible to reduce incidence of eclampsia measuring arterial blood pressure daily during antenatal period and for at least 14-days postpartum appears to be necessary for diagnosis and treatment for all cases of hypertension.

Other case studies $[1,21,40,44,52,60,69,117,141-153]$ illustrate the importance of surgical management of pheochromocytoma in second trimester of pregnancy to avoid catastrophic complications later in pregnancy, high rate of emergency caesarean sections than the elective ones and high prevalence of HCB \& HBV among pregnant women etc.

Some other papers [154-249] also deal with maternal and neonatal mortality, however the same is not specific to $\mathrm{PE} / \mathrm{E}$.

\section{Discussion}

Skilled based training of the health care providers is crucially important to improve emergency Obstetric and Newborn Care. Along with it continual training and skill-building of TBAs and community health workers is also essential. All should specifically be trained on how to screen pregnant mothers during ANC visits to detect signs of $\mathrm{PE} / \mathrm{E}$ and how to administer $\mathrm{MgSO}_{4}$ to patients who are in need of anticonvulsant therapy. Before training, training need assessment should be conducted specifically to assess gaps in knowledge and practices.

It is critically important to improve quality of care with regards to the management of PE/E in Pakistan by developing clinical operational guidelines/protocols. Since there is no endorsed guideline/protocol available at national, provincial or regional level, it is the dire need of time to do so. White Ribbon Alliance-WRA Pakistan has formulated Trainees' Manual on the use of Magnesium Sulphate as a first line-treatment in severe Pre-eclampsia and Eclampsia, Pakistan ${ }^{11}$. These guidelines are for doctors

\footnotetext{
11 USE OF MAGNESIUM SULPHATE AS A FIRST LINE TREATMENT IN SEVERE PRE-ECLAMPSIA AND

ECLAMPSIA-Trainees' Manual for Health Care Professionals-White Ribbon Alliance and Research and Advocacy Fund-RAF Pakistan
} 
working at primary, secondary and tertiary care health facilities. Chapter 5 of this manual illustrates Use of Magnesium Sulphate in detail.

In addition to it WHO Recommendations for Prevention and treatment of Pre-eclampsia and Eclampsia are there which also highlight use of Magnesium Sulphate as an effective remedy for PE/E. After evidence, magnesium sulfate was found to be associated with significant reduction both statistically and clinically, in the risk of eclampsia by $59 \%$ as compared to placebo and other anticonvulsants.

This shows need for enhanced use of magnesium sulphate for PE/E management with proper guidelines available.

Along with an increase in ANC, skilled delivery, PNC, family planning and nutritional status of mothers would further improve the situation. Gender equality, women empowerment and livelihood programs are also not an exception.

In order to understand the actual situation of PE/E in Pakistan it is important to adopt evidence-based approach and initiate community studies. Community studies through accurate, historical and contextual analysis of community health would enable to understand psycho-social, socio-cultural and socio-economic determinants of PE/E at one hand and barriers to address PE/E at the other. Through grass-root level Research (investigation and observation) at an extensive scale, actual situation can be understood along with adequacy of underway interventions, challenges/barriers and required reforms to prevent and cure PE/E in the country. Allocation of sufficient resources should be made under community studies in all PE/E related interventions therefore.

\section{Research Gaps}

None of the studies is adequately and specifically depicting barriers in the availability, preparation, use and follow up of MgSO4 for managing and treating PE/E in Pakistan.

Likewise no study is adequately highlighting how to enhance the use of MgSO4 in Pakistan. Moreover adequate focus of all studies regarding the training of health care providers on the preparation and use of MgSO4 is also missing. The research studies have also not vigorously highlighted the importance of having national level clinical guidelines for the use of MgSO4.

\section{Gaps in the Knowledge Base}

Knowledge on the use of $\mathrm{MgSO}_{4}$ to treat $\mathrm{PE} / \mathrm{E}$ is there as far as health care providers are concerned. However, use of $\mathrm{MgSO}_{4}$ is low. $\mathrm{MgSO}_{4}$ is critically under-utilized in Pakistan. There is a lack of information on context-specific health system barriers that prevents optimal use of this life-saving medicine in Pakistan. Future research needs to be made in this regard as only one paper under review is significantly highlighting these barriers.

Likewise no paper is showing the impact of the use of $\mathrm{MgSO}_{4}$ so that the findings could be disseminated to all stakeholders to maximize the use of medicines. Only one study has shown reasons for the low use of this medicine in detail [122]. This paper has also described some guidelines on the preparation of this medicine [122]. 
Similarly no study contains any guideline on the use of $\mathrm{MgSO}_{4}$ though a number of studies have identified the importance of guideline formulation. In the same context, no report significantly describes about frequency of $\mathrm{MgSO}_{4}$ utilization in the health facilities of Pakistan, causes of its low use, demand and supply side interventions of $\mathrm{MgSO}_{4}$, knowledge of health care providers and their willingness on the use of $\mathrm{MgSO}_{4}$, impact of $\mathrm{MgSO}_{4}$ usages (where this medicine has been and is being used), challenges and required reforms in the health care system to make this medicine well utilized. Therefore there are gaps in the evidence.

There is a positive link between Vitamin D deficiencies and Preeclampsia. Vitamin D supplementation can reduce pre-eclampsia. However, further research needs to be conducted to establish this relationship.

In addition to the above, literature is also highlighting research gaps and future research areas. Studies should be conducted to assess: excessive use of micronutrients during pregnancy [189], triage of preterm and growth restricted infants [131], benefits of calcium supplementation and aspirin to prevent still birth [82, examine clinical benefits of vitamin $\mathrm{B}_{6}$ supplementation in pregnancy and/or labour [177, 194], minimize newly recognized risk factors for stillbirth including periodontal [38], assess the effect of psychotic symptoms with seizure control [202] and assess differences in intraoperative and postoperative hemorrhage when misoprostol is compared to oxytocin [106].

\section{Conclusion and Recommendations}

Key recommendations from the identified and reviewed literature are as under:-

MgSO4 is still not in widespread use in Pakistan though it is the best treatment for the management of $\mathrm{PE} / \mathrm{E}$ according to WHO. Future researches should explore the followings areas in detail:

$>$ Barriers to the availability of MgSO4 at all levels

$>$ How to scale up the use of MgSO4 in Pakistan

$>$ Formulation and use of national level clinical guidelines on the use of MgSO4

$>$ Inadequate training of health care providers on managing and treating $\mathrm{PE} / \mathrm{E}$

$>$ Inadequate training of health care providers on the preparation and use of $\mathrm{MgO} 4$

$>$ Cost effectiveness of MgSO4

22 (C) 2016 The Population Council, Inc. 


\section{End notes}

1. World Health Organization (WHO) Make Every Mother and Child Count. The World Health Report 2005. Geneva: World Health Organization1.

2. World Health Organization WHO recommendations for prevention and treatment of preeclampsia and eclampsia. 2011, WHO. Geneva².

3. National Institute of Population Studies: Pakistan Demographic and Health Survey 2012-13. Report; 2013. URL: https://dhsprogram.com/pubs/pdf/FR290/FR290.pdf ${ }^{3}$

4. Pakistan Demographic and Health Survey 2006-074

5. Kassebaum NJ et al. Global, regional and national levels and causes of maternal mortality during 1990-2013: a systematic analysis for the Global Burden of Disease Study 2013. Lancet; 2014. 13; 384 (9947):980-1004. 5

6. World Bank, Koblinsky M. Editor, Reducing Maternal Mortality. Learning from Bolivia, China, Egypt, Honduras, Indonesia, Jamaica, and Zimbabwe. Human Development Network, Health, Nutrition, and Population Series. The World Bank, Washington D.C. 20036

7. Abouzahr C. Critical issues in safe motherhood, 110- 134, Geneva, WHO, 1999. 7

8. Virginia Apgar invented the Apgar score in 1952 as a method to quickly summarize the health of newborn children. ${ }^{8}$

9. through weight measurement after birth. ${ }^{9}$

10. Soluble fms-like tyrosine kinase-1 (sFlt-1 or sVEGFR-1) is a tyrosine kinase protein that disables proteins that cause blood vessel growth. ${ }^{10}$

11. Placental growth factor 11

12. Use of Magnesium Sulphate as A First Line Treatment in Severe Pre-Eclampsia AndeclampsiaTrainees' Manual for Health Care Professionals-White Ribbon Alliance and Research and Advocacy Fund-RAF Pakistan ${ }^{12}$

23 (C) 2016 The Population Council, Inc. 


\section{References}

1. Shamsi, U., Hatcher, J., Shamsi, A., Zuberi, N., Qadri, Z. and Saleem, S., 2010. A multicentre matched case control study of risk factors for preeclampsia in healthy women in Pakistan. BMC women's health, 10(1), p.1.

2. Feerasta, S.H., Motiei, A., Motiwala, S. and Zuberi, N.F., 2000. Uterine atony at a tertiary care hospital in Pakistan: a risk factor analysis. JPMA. The Journal of the Pakistan Medical Association, 50(4), pp.132-136.

3. Risk factors for pre-eclampsia at antenatal booking: systematic review of controlled studies BMJ 2005; 330 doi: http://dx.doi.org/10.1136/bmj. 38380.674340.EO (Published 10 March 2005)

4. Imran, N. and Haider, I.I., 2010. Screening of antenatal depression in Pakistan: risk factors and effects on obstetric and neonatal outcomes. Asia-Pacific Psychiatry, 2(1), pp.26-32.

5. Halimi, S. and Halimi, S.M.A., 2010. Eclampsia and its association with external factors. J. Ayub. Med. Coll. Abbottabad, 22(3).

6. Shaikh Samiullah, M.H., Hanif, G., Ghouri, A.A. and Shaikh, K., Etiological patterns of stroke in young patients at a tertiary care hospital. Age,50(25.7200), pp.6-5622.

7. Qureshi, I.A., Xi, X.R. and Yaqob, T., 2000. The ocular hypotensive effect of late pregnancy is higher in multigravidae than in primigravidae. Graefe's archive for clinical and experimental ophthalmology, 238(1), pp.64-67.

8. Qureshi, Z. and Khan, R., 2015. Dietary Intake Trends among Pregnant Women in Rural Area of Rawalpindi, Pakistan. Journal of Ayub Medical College Abbottabad, 27(3), pp.684-688.

9. Qazi, G., 2011. Obstetric and perinatal outcome of multiple pregnancy. J Coll Physicians Surg Pak, 21(3), pp.142-5.

10. Rizwan, N., Abbasi, R.M. and Mughal, R., 2010. Maternal morbidity and perinatal outcome with twin pregnancy. J Ayub Med Coll Abbottabad, 22(2), pp.105-107.

11. Qureshi, I.A., Xi, X.R. and Yaqob, T., 2000. The ocular hypotensive effect of late pregnancy is higher in multigravidae than in primigravidae. Graefe's archive for clinical and experimental ophthalmology, 238(1), pp.64-67.

12. Aziz, S. and Soomro, N., 2012. Twin births and their complications in women of low socioeconomic profile. J Pak Med Assoc, 62(11), pp.1204-8.

13. Obstetric and perinatal outcome of multiple pregnancy, Journal of the College of Physicians and Surgeons, Pakistan. 2011 Mar; 21(3):142-5, Qazi G, http://www.popline.org/node/223008 
14. Salam, R.A., Das, J.K. and Bhutta, Z.A., 2014. Impact of intrauterine growth restriction on long-term health. Current Opinion in Clinical Nutrition \& Metabolic Care, 17(3), pp.249-254.

15. Ali, H.S., 2009. Assessment of amniotic fluid index in normal pregnancy at a tertiary care hospital setting. J Ayub Med Coll Abbottabad, 21(3), pp.149-151.

16. Hasan, J.A., Qureshi, A., Ramejo, B.B. and Kamran, A., 2010. Peripartum cardiomyopathy characteristics and outcome in a tertiary care hospital.JPMA. The Journal of the Pakistan Medical Association, 60(5), p.377.

17. Pre-eclampsia and lipid profile, Pakistan Journal of Medical Sciences. 2007 Oct-Dec; 23(5):751-754, Aziz R; Mahboob T. http://www.popline.org/node/198122

18. Imdad, A., Jabeen, A. and Bhutta, Z.A., 2011. Role of calcium supplementation during pregnancy in reducing risk of developing gestational hypertensive disorders: a metaanalysis of studies from developing countries. BMC public health, 11(3), p.1.

19. Munazza, B., Raza, N., Naureen, A., Khan, S.A., Fatima, F., Ayub, M. and Sulaman, M., 2011. Liver function tests in preeclampsia. J Ayub Med Coll Abbottabad, 23(4), pp.35.

20. Ainuddin, J.A., Karim, N., Zaheer, S., Ali, S.S. and Hasan, A.A., 2015. Metformin Treatment in Type 2 Diabetes in Pregnancy: An Active Controlled, Parallel-Group, Randomized, Open Label Study in Patients with Type 2 Diabetes in Pregnancy. Journal of diabetes research, 2015.

21. Nawaz, F.H. and Rizvi, J., 2010. Continuation of metformin reduces early pregnancy loss in obese Pakistani women with polycystic ovarian syndrome.Gynecologic and obstetric investigation, 69(3), pp.184-189.

22. Zafar, A.N., Khan, S. and Zafar, S.N., 2013. Factors associated with breast arterial calcification on mammography. J Coll Physicians Surg Pak, 23(3), pp.178-81.

23. Akseer, N., Kamali, M., Husain, S., Mirza, M., Bakhache, N. and Bhutta, Z.A., 2015. Strategies to avert preventable mortality among mothers and children in the Eastern Mediterranean Region: new initiatives, new hope.Eastern Mediterranean Health Journal, 21(5), p.361.

24. Effects of poverty on pregnant women, Pakistan, Journal of Medical Research. 2012 Jan-Mar; 51(1):5-9, Aftab S; Ara J; Kazi S; Deeba F. http://www.popline.org/node/551799

25. Eclampsia, a major cause of maternal and perinatal mortality: a prospective analysis at a tertiary care hospital of Peshawar, JPMA. Journal of the Pakistan Medical Association. 2003 Aug,Shaheen B; Hassan L; Obaid M. http://www.popline.org/apachesolr-angularjs-search/mk9_ByrXA-K6xegGmro 
26. Obstetric services in Pakistan: where are we and what is the way forward [editorial],Rawal Medical Journal. 2013 Jan-Mar; 38(1):1-2, Mazhar SB. http://www.popline.org/node/581656

27. Perveen, S., 2014. Frequency and impact of hypertensive disorders of pregnancy. Journal of Ayub Medical College, 26, pp.518-521.

28. Riaz, S., Habib, S. and Jabeen, A., 2011. Frequency of maternal mortality and morbidity in pregnancy-induced hypertension. J Ayub Med Coll Abbottabad, 23(4), pp.61-3.

29. Khan, B., Deeba, F. and Khattak, S.N., 2012. Maternal Mortality: A ten year review in a tertiary care setup. J Ayub Med Coll Abbottabad, 24(3-4), pp.124-7.

30. An audit and trends of perinatal mortality at the Jinnah Postgraduate Medical Centre, Karachi, Journal of Pakistan Medical Association. 2007 Apr; 57(4):168-171, Korejo R; Bhutta S; Noorani KJ; Bhutta ZA. http://www.popline.org/node/190076

31. Akhlaq, M., Nagi, A.H. and Yousaf, A.W., 2012. Placental morphology in pre-eclampsia and eclampsia and the likely role of NK cells. Indian Journal of Pathology and Microbiology, 55(1), p.17.

32. Begum, S. and Aziz-un-Nisa, B.I., 2003. Analysis of maternal mortality in a tertiary care hospital to determine causes and preventable factors. J Ayub Med Coll Abbottabad, 15(2), pp.49-52.

33. Fawad, A., Naz, H., Islam, A., Zaffar, S. and Abbasi, A.U.N., 2011. Maternal mortality in a tertiary care hospital. Journal of Ayub Medical College Abbottabad, 23(1), pp.9295.

34. Frequency of eclampsia and maternal complications in a tertiary care facility of Peshawar, Pakistan, Journal of Medical Research. 2008 Oct-Dec; 47(4):79-82, Ahmad S; Nazli R; Lutfullah G. $\quad$ http://www.popline.org/node/205312

35. Afzal, E., Sherin, F. and Seema, N., 2015. Correlation of Adverse Perinatal Outcomes and Placental Infarcts in Hypertensive Preterm Pregnancies. Journal of Ayub Medical College Abbottabad, 27(3), pp.647-649.

36. Munim, S., Haq Nawaz, F. and Ayub, S., 2011. Still births-eight years experience at Aga Khan University Hospital Karachi, Pakistan. The Journal of Maternal-Fetal \& Neonatal Medicine, 24(3), pp.449-452.

37. Jan, M.R., Nazli, R., Shah, J. and Akhtar, T., 2012. A study of lipoproteins in normal and pregnancy induced hypertensive women in tertiary care hospitals of the North West Frontier Province-Pakistan. Hypertension in pregnancy,31(2), pp.292-299.

38. Menezes, E.V., Yakoob, M.Y., Soomro, T., Haws, R.A., Darmstadt, G.L. and Bhutta, Z.A., 2009. Reducing stillbirths: prevention and management of medical disorders and infections during pregnancy. BMC Pregnancy and Childbirth, 9(Suppl 1), p.S4. 
39. Ayaz, A., Muhammad, T., Hussain, S.A. and Habib, S., 2009. Neonatal outcome in preeclamptic patients. J Ayub Med Coll Abbottabad, 21(2), pp.53-55.

40. Hossain, N., Khan, N. and Khan, N., 2009. Obstetric causes of stillbirth at low socioeconomic settings. JPMA, 59(11), pp.744-747.

41. Begum, S. and Aziz-un-Nisa, B.I., 2003. Analysis of maternal mortality in a tertiary care hospital to determine causes and preventable factors.J Ayub Med Coll Abbottabad, 15(2), pp.49-52.

42. Khan, M. and Wasay, M., 2013. Haemorrhagic strokes in pregnancy and puerperium. International Journal of Stroke, 8(4), pp.265-272.

43. Siddiqui, S.A., Soomro, N. and Hasnain, F.S., 2012. Severe obstetric morbidity and its outcome in patients presenting in a tertiary care hospital of Karachi. JPMA-Journal of the Pakistan Medical Association, 62(3), p.226.

44. Hassan, I., Junejo, A.M. and Dawani, M.L., 2009. Etiology and outcome of acute renal failure in pregnancy. J Coll Physicians Surg Pak, 19(11), pp.714-7.

45. Shams, F., Rafique, M., Samoo, N.A. and Irfan, R., 2012. Fibrinoid necrosis and hyalinization observed in normal, diabetic and hypertensive placentae. $J$ Coll Phys Surg Pak, 22(12), pp.769-772.

46. Sherin, F., Afzal, E. and Seema, N., 2015. GROSS MORPHOLOGICAL CHANGES IN PREMATURE AND POST MATURE HUMAN PLANCENTAE.Journal of Ayub Medical College Abbottabad, 27(2), pp.448-450.

47. Ashfaq, M., Janjua, M.Z. and Channa, M.A., 2005. Effect of gestational diabetes and maternal hypertension on gross morphology of placenta. $J$ Ayub Med Coll Abbottabad, 17(1), pp.44-7.

48. Bentata, Y., Housni, B., Mimouni, A., Azzouzi, A. and Abouqal, R., 2012. Acute kidney injury related to pregnancy in developing countries: etiology and risk factors in an intensive care unit. J Nephrol, 25(5), pp.764-775.

49. Rizwan, N. and Uddin, S.F., 2011. Obstetrical acute renal failure: a challenging medical complication. J Ayub Med Coll Abbottabad, 23(4), pp.66-68.

50. Rizwan, N. and Uddin, S.F., 2011. Obstetrical acute renal failure: a challenging medical complication. J Ayub Med Coll Abbottabad, 23(4), pp.66-68.

51. Ansari, M.R., Laghari, M.S. and Solangi, K.B., 2008. Acute renal failure in pregnancy: one year observational study at Liaquat University Hospital, Hyderabad. JPMA. The Journal of the Pakistan Medical Association, 58(2), p.61.

52. Wali, R., 2009. Aetiology, maternal and foetal outcome in 60 cases of obstetrical acute renal failure. J Ayub Med Coll Abbottabad, 21(4). 
53. Acute renal failure in pregnancy: One year observational study at Liaquat University Hospital, Hyderabad, JPMA. Journal of the Pakistan Medical Association. 2008 Feb; 58(2):61-64,Ansari MR; Laghari MS; Solangi KB. http://www.popline.org/node/198931

54. Bibi, S., Ghaffar, S., Pir, M.A. and Yousfani, S., 2009. Risk factors and clinical outcome of placental abruption: a retrospective analysis. Shock, 22, p.20.

55. Co-relation of pregnancy induced hypertension with placental abruption and effect of antihypertensive therapy, JPMA. Journal of the Pakistan Medical Association. 2005 Jul-Dec; 30(2):[4] p,Tasleem H; Tasleem S; Adil MM; Siddique M; Waheed K. http://www.popline.org/node/266353

56. Co-relation of pregnancy induced hypertension with placental abruption and effect of antihypertensive therapy, JPMA. Journal of the Pakistan Medical Association. 2005 Jul-Dec; 30(2):[4] p,Tasleem H; Tasleem S; Adil MM; Siddique M; Waheed K. http://www.popline.org/node/266353

57. Comparison of predictive value of 8,12 and 24-hour proteinuria in pre-eclampsia, Pakistan, Journal of Medical Sciences. 2007 Apr-Jun; 23(2):182-184, Rabiee S. http://www.popline.org/node/186320

58. Ali, Z., Ahmed, S.M., Bhutto, A.R., Chaudhry, A. and Munir, S.M., 2012. Peripheral artery disease in type II diabetes. J Coll Physicians Surg Pak, 22, pp.686-689.

59. Korejo, R., Bhutta, S., Noorani, K.J. and Bhutta, Z.A., 2007. An audit and trends of perinatal mortality at the Jinnah Postgraduate Medical Centre, Karachi. Parity, 31(40), p.40.

60. Khan, N. and Jamal, M., 2003. Maternal risk factors associated with low birth weight. Journal of the College of Physicians and Surgeons--Pakistan: JCPSP, 13(1), pp.25-28.

61. Qureshi, S.B., Ahmad, M., Qureshi, P.M.A., Memon, A. and Qazi, R.A., 2010. Hyperhomocysteinaemia, vascular related pregnancy complications and the response to vitamin supplementation in pregnant women of Pakistan. JPMA. The Journal of the Pakistan Medical Association, 60(9), p.741.

62. Ahmed, N., Anwar, W. and Waqas, H., 2009. Obesity, hyperlipidemia, and hyperuraecemia in young and old hypertensive patients. J Ayub Med Coll Abbottabad, 21(4), pp.53-6.

63. Ali, A., Ali, M.A. and Ali, M.U., 2010. Obstetrical Associated Renal, Cortical Necrosis: Though Uncommon but not Rare!.J Ayub Med Coll Abbottabad, 22(3).

64. Mumtaz, F., Memon, A.R., Yousfani, S., Tahir, S.M., Khushk, I., Memon, M. and Memon, A., 2008. Role of serum leptin level as a marker of severity of pre eclampsia. J Ayub Med Coll Abbottabad, 20(1), pp.13-5. 
65. Ashraf, M., Sher, Z. and Irum, N., 2012. Bleeding disorders in obstetrics and gynaecological practice. Journal of the College of Physicians and Surgeons--Pakistan: JCPSP, 22(3), pp.192-193.

66. Placental Abruption and Subsequent Risk of Pre-eclampsia: A Population-Based Case-Control Study, Samantha E. Parker1,*, Martha M. Werler1, Mika Gissler2,4, Minna Tikkanen3 andCande V. Ananth

67. Naeem, M., Khan, M.Z., Abbas, S.H., Khan, A., Adil, M. and Khan, M.U., 2015. Rate and indications of elective and emergency caesarean section; a study in a tertiary care hospital of peshawar. J Ayub Med Coll Abbottabad,27(1), pp.151-4.

68. Ghazi, A., Karim, F., Hussain, A.M., Ali, T. and Jabbar, S., 2012. Maternal morbidity in emergency versus elective caesarean section at tertiary care hospital. J Ayub Med Coll Abbottabad, 24(1), pp.10-13.

69. Yousaf, U.F., Hayat, S. and Afzal, N., 2015. Resuscitation of Newborn in High Risk Deliveries. Journal of Ayub Medical College Abbottabad, 27(2), pp.343-345.

70. Causes of maternal deaths in a tertiary care hospital in Larkana, Pakistan, Rawal Medical Journal. $2013 \quad$ Jul-Sept; Soomro S; Naz S; Memon N; Baloch R. http://www.popline.org/node/581654

71. Maternal mortality in a tertiary care hospital, Journal of Ayub Medical College, Abbottabad. 2011 Jan-Mar; 23(1):92-5, Fawad A; Naz H; Islam A; Zaffar S; Abbasi AU. http://www.popline.org/node/574739

72. A study of caesarean birth in a teaching hospital, Pakistan, Journal of Medical Research. 2002 Jul-Sep; 41(3):118-122, Ahmad N; Mehboob R. http://www.popline.org/node/247204

73. Shaheen, B., Hassan, L. and Obaid, M., 2003. Eclampsia, a major cause of maternal and perinatal mortality: a prospective analysis at a tertiary care hospital of Peshawar. JPMA. The Journal of the Pakistan Medical Association, 53(8), pp.346350.

74. Bano, N., Chaudhri, R., Yasmeen, L., Shafi, F. and Ejaz, L., 2011. A study of maternal mortality in 8 principal hospitals in Pakistan in 2009. International Journal of Gynecology \& Obstetrics, 114(3), pp.255-259.

75. Arain, N., Mirza, W.A. and Aslam, M., 2015. Vitamin D and the prevention of preeclampsia: A systematic review. Pak. J. Pharm. Sci, 28(3), pp.1015-1021.

76. Hossain, N., Kanani, F.H., Ramzan, S., Kausar, R., Ayaz, S., Khanani, R. and Pal, L., 2014. Obstetric and neonatal outcomes of maternal vitamin D supplementation: results of an open-label, randomized controlled trial of antenatal vitamin D supplementation in Pakistani women. The Journal of Clinical Endocrinology \& Metabolism, 99(7), pp.2448-2455. 
77. Haider, B.A. and Bhutta, Z.A., 2006. Multiple-micronutrient supplementation for women during pregnancy. Cochrane Database Syst Rev, 4(4).http://apps.who.int/rhl/reviews/langs/CD004905.pdf

78. Imdad, A. and Bhutta, Z.A., 2012. Effects of calcium supplementation during pregnancy on maternal, fetal and birth outcomes. Paediatric and perinatal epidemiology, 26(s1), pp.138-152.

79. Imdad, A., Jabeen, A. and Bhutta, Z.A., 2011. Role of calcium supplementation during pregnancy in reducing risk of developing gestational hypertensive disorders: a metaanalysis of studies from developing countries. BMC public health, 11(3), p.1.

80. Imdad, A. and Bhutta, Z.A., 2012. Effects of calcium supplementation during pregnancy on maternal, fetal and birth outcomes. Paediatric and perinatal epidemiology, 26(s1), pp.138-152.

81. Imdad, A. and Bhutta, Z.A., 2012. Effects of calcium supplementation during pregnancy on maternal, fetal and birth outcomes. Paediatric and perinatal epidemiology, 26(s1), pp.138-152.

82. Jabeen, M., Yakoob, M.Y., Imdad, A. and Bhutta, Z.A., 2011. Impact of interventions to prevent and manage preeclampsia and eclampsia on stillbirths. BMC Public Health, 11(Suppl 3), p.S6.

83. Yakoob, M.Y., Lawn, J.E., Darmstadt, G.L. and Bhutta, Z.A., 2010, December. Stillbirths: epidemiology, evidence, and priorities for action. InSeminars in perinatology (Vol. 34, No. 6, pp. 387-394). WB Saunders.

84. J Ayub Med Coll Abbottabad. 2011 Oct-Dec;23(4):111-3

85. Stillbirths in an urban community in Pakistan, American Journal of Obstetrics and Gynecology. 2007 Sep; 197(3):257.e1-257.e8, Jehan I; McClure EM; Salat S; Rizvi S; Pasha 0. http://www.popline.org/node/194349

86. Menezes, E.V., Yakoob, M.Y., Soomro, T., Haws, R.A., Darmstadt, G.L. and Bhutta, Z.A., 2009. Reducing stillbirths: prevention and management of medical disorders and infections during pregnancy. BMC Pregnancy and Childbirth, 9(Suppl 1), p.S4.

87. Stillbirths: what difference can we make and at what cost?, The Lancet, Volume 377, Issue 9776, 30 April-6 May 2011, Pages 1523-1538, Zulfiqar A Bhutta, Mohammad Yawar Yakoob, Joy E Lawn, Arjumand Rizvi, Ingrid K Friberg, Eva Weissman, Eckhart Buchmann, Robert L Goldenberg, for 's Stillbirths Series steering committee. http://www.sciencedirect.com/science/article/pii/S0140673610622696

88. Ganga Ram Hospital, Lahore, Pakistan

89. Mazhar, S.B., Batool, A., Emanuel, A., Khan, A.T. and Bhutta, S., 2015. Severe maternal outcomes and their predictors among Pakistani women in the WHO 
Multicountry Survey on Maternal and Newborn Health. International Journal of Gynecology \& Obstetrics, 129(1), pp.30-33.

90. Fikree, F.F., Mir, A.M. and Haq, I.U., 2006. She may reach a facility but will still die! An analysis of quality of public sector maternal health services, District Multan, Pakistan. JOURNAL-PAKISTAN MEDICAL ASSOCIATION,56(4), p.156.

91. She may reach a facility but will still die! An analysis of quality of public sector maternal health services, District Multan, Pakistan, JPMA. Journal of the Pakistan Medical Association. 2006 Apr; 56(4):156-163,Fikree FF; Mir AM; Haq IU. http://www.popline.org/node/170927

92. Mazhar, S.B., Batool, A., Emanuel, A., Khan, A.T. and Bhutta, S., 2015. Severe maternal outcomes and their predictors among Pakistani women in the WHO Multicountry Survey on Maternal and Newborn Health. International Journal of Gynecology \& Obstetrics, 129(1), pp.30-33.

93. Screening of pregnant women for gestational diabetes mellitus, JAMC. Journal of Ayub Medical College, Abbottabad. 2005 Apr-Jun; 17(2):5458,Hassan A. http://www.popline.org/node/255975

94. Rohra, D.K., Zeb, A., Qureishi, R.N., Azam, S.I., Khan, N.B., Zuberi, H.S. and Sikandar, R., 2012. Prediction of pre-eclampsia during early pregnancy in primiparas with soluble fms-like tyrosine kinase-1 and placental growth factor. National Medical Journal of India, 25(2), p.68.

95. Obstetrical risks in the older primigravida, Journal of the College of Physicians and Surgeons, Pakistan. 2004 May; 14(5):[6] p..,Naqvi MM; Naseem A. http://www.popline.org/node/254167

96. Severe maternal morbidity at Pakistan Institute of Medical Sciences. The nearmiss concept -- an indicator of maternal care, Pakistan's population issues in the 21st century. Conference proceedings Oct 24th - 26th, 2000, Karachi, [compiled by] Population Association of Pakistan, Mahmood G; Rafay A; Haq A. http://www.popline.org/node/187715

97. Zafar, A. and Ali, Z., 2012. Pattern of magnetic resonance imaging and magnetic resonance venography changes in cerebral venous sinus thrombosis. J Ayub Med Coll Abbottabad, 24(1), pp.63-67.

98. Naz, F., Malik, S., Mehmood, T. and Tariq, S., 2012. Postnatal encephalitis: a diagnosis not to be missed. Journal of Ayub Medical College, Abbottabad,24, pp.7780.

99. Magnesium Sulphate in The Prophylaxis And Treatment of ECLAMPSIA Shehla Noor*, Mussarat Halimi, Nasreen Ruby Faiz, Fouzia Gull, Nasreen Akbar

100. Magnesium sulfate treatment for the prevention of eclampsia: A brief review

101. Use of Magnesium Sulphate as A First Line Treatment in Severe PreEclampsia And Eclampsia 
102. Barriers to the use of Magnesium Sulphate Barriers to the Use of Magnesium Sulphate in Pakistan- in Pakistan- a Study to develop informed a study to Develop Informed Policy

103. Fawad, S., 2010. Role of Anti-Thrombotic Therapy for Recurrent Pregnancy Loss Due To Anti-Phospholipid Syndrome. J Ayub Med Coll Abbottabad,22(3), p.3.

104. Sultana, R., Bashir, R. and Khan, B., 2005. Presentation and management outcome of eclampsia at Ayub Teaching Hospital, Abbottabad. Hypertension,62, pp.9-17.

105. Sultana, R., Bashir, R. and Khan, B., 2005. Presentation and management outcome of eclampsia at Ayub Teaching Hospital, Abbottabad. Hypertension,62, pp.9-17.

106. Misoprostol to reduce intraoperative and postoperative hemorrhage during cesarean delivery: a systematic review and metaanalysis, American Journal of Obstetrics and Gynecology, Volume 209, Issue 1, July 2013, Pages 40.e1-40.e17, Agustín Conde-Agudelo, Aníbal Nieto, Anyeli Rosas-Bermudez,Roberto Romero. http://www.sciencedirect.com/science/article/pii/S0002937813002809

107. Mobeen, N., Durocher, J., Zuberi, N.F., Jahan, N., Blum, J., Wasim, S., Walraven, G. and Hatcher, J., 2011. Administration of misoprostol by trained traditional birth attendants to prevent postpartum haemorrhage in homebirths in Pakistan: a randomised placebo-controlled trial. BJOG: An International Journal of Obstetrics \& Gynaecology, 118(3), pp.353-361.

108. Ainuddin, J., Karim, N., Hasan, A.A. and Naqvi, S.A., 2015. Metformin versus insulin treatment in gestational diabetes in pregnancy in a developing country. A randomized control trial. diabetes research and clinical practice,107(2), pp.290299.

109. Metformin versus insulin treatment in gestational diabetes in pregnancy in a developing country. A randomized control, Diabetes Research and Clinical Practice, Volume 107, Issue 2, February 2015, Pages 290-299, Jahanara Ainuddin, Nasim Karim, Anjum Ara Hasan, Sanower Ali Naqvi. http://www.sciencedirect.com/science/article/pii/S0168822714004616

110. Nawaz, F.H., Khalid, R., Naru, T. and Rizvi, J., 2008. Does continuous use of metformin throughout pregnancy improve pregnancy outcomes in women with polycystic ovarian syndrome?. Journal of Obstetrics and Gynaecology Research, 34(5), pp.832-837.

111. Takreem, A., 2015. COMPARISON OF PERITONEAL CLOSURE VERSUS NONCLOSURE DURING CAESAREAN SECTION. Journal of Ayub Medical College, Abbottabad: JAMC, 27(1), p.78.

112. Obstetric and neonatal outcomes of maternal vitamin $D$ supplementation: results of an open-label, randomized controlled trial of antenatal vitamin D supplementation in Pakistani women, Journal of Clinical Endocrinology and 
Metabolism. 2014 Jul; 99(7):2448-55. Hossain N; Kanani FH; Ramzan S; Kausar R; Ayaz S; Khanani R; Pal L. $\quad$ http://www.popline.org/node/623787

113. Still births--eight years experience at Aga Khan University Hospital Karachi, Pakistan.

Journal of Maternal - Fetal and Neonatal Medicine. 2011 Mar; 24(3):449-52,Munim S; Nawaz FH; Ayub S. http://www.popline.org/node/221487

114. Third delay of maternal mortality in a tertiary hospital, JPMA. Journal of the Pakistan Medical Association. 2007 Jul-Dec; 32(2):1-11, Shah N; Khan NH. http://www.popline.org/node/198142

115. Qureshi, I.A., Xi, X.R. and Wu, X.D., 1996. Intraocular pressure trends in pregnancy and in the third trimester hypertensive patients. Acta obstetricia et gynecologica Scandinavica, 75(9), pp.816-819.

116. Mumtaz, F., Memon, A.R., Yousfani, S., Tahir, S.M., Khushk, I., Memon, M. and Memon, A., 2008. Role of serum leptin level as a marker of severity of pre eclampsia. J Ayub Med Coll Abbottabad, 20(1), pp.13-5.

117. Sadaf, N., Haq, G. and Shukar-ud-Din, S., 2013. Maternal and foetal outcome in HELLP syndrome at tertiary care hospital. Blood transfusion, 23, pp.57-5.

118. Bigdeli, M., Zafar, S., Assad, H. and Ghaffar, A., 2013. Health system barriers to access and use of magnesium sulfate for women with severe pre-eclampsia and eclampsia in Pakistan: evidence for policy and practice. PloS one, 8(3), p.e59158.

119. Health system barriers to access and use of magnesium sulfate for women with severe pre-eclampsia and eclampsia in Pakistan: evidence for policy and practice, PloS One. 2013; 8(3):e59158, Bigdeli M; Zafar S; Assad H; Ghaffar A. http://www.popline.org/node/576417

120. Maternal and perinatal outcomes among women with eclampsia admitted to a tertiary care hospital in Hyderabad, Pakistan, International Journal of Gynaecology and Obstetrics. 2013 Dec; 123(3):247-8, Rizwan N; Rauf S; Farhan-Uddin S. http://www.popline.org/node/582083

121. Health System Barriers to Access and Use of Magnesium Sulfate for Women with Severe Pre-Eclampsia and Eclampsia in Pakistan: Evidence for Policy and Practice

122. USE OF MAGNESIUM SULPHATE AS A FIRST LINE TREATMENT IN SEVERE PREECLAMPSIA AND ECLAMPSIA

123. Jafarey, S.N., 2002. Maternal mortality in Pakistan--compilation of available data. JPMA. The Journal of the Pakistan Medical Association, 52(12), pp.539-544.

124. Utz, B., Zafar, S., Arshad, N., Kana, T., Gopalakrishnan, S. and van den Broek, N., 2015. Status of emergency obstetric care in four districts of Punjab, Pakistanresults of a baseline assessment. JPMA. The Journal of the Pakistan Medical Association, 65(5), pp.480-485. 
125. Utz, B., Siddiqui, G., Adegoke, A. and Broek, N., 2013. Definitions and roles of a skilled birth attendant: a mapping exercise from four South-Asian countries. Acta obstetricia et gynecologica Scandinavica, 92(9), pp.1063-1069.

126. Status of emergency obstetric care in four districts of Punjab, Pakistan - results of a baseline assessment, JPMA. Journal of the Pakistan Medical Association. 2015 May; 65(5):480-5, Utz B; Zafar S; Arshad N; Kana T; Gopalakrishnan S. http://www.popline.org/node/643058

127. Bibi, S., Memon, A., Sheikh, J.M. and Qureshi, A.H., 2008. Severe acute maternal morbidity and intensive care in a public sector university hospital of Pakistan. $J$ Ayub Med Coll Abbottabad, 20(1), pp.109-12.

128. Maternal mortality: a ten year review in a tertiary care setup, Journal of Ayub Medical College, Abbottabad. 2012 Jul-Dec; 24(3-4):124-7, Khan B; Deeba F; Khattak SN. http://www.popline.org/node/581939

129. General anaesthesia for emergency caesarian section in a patient with Eisenmenger's Syndrome and pre-eclampsia, JPMA. Journal of the Pakistan Medical Association. 2005 Aug; 55(8):348-350, Hussain AM; Ismail S; Kamal RS. http://www.popline.org/node/256120

130. Jafree, S.R., Zakar, R. and Zakar, M.Z., 2015. Factors Associated with Low Birth Weight of Children Among Employed Mothers in Pakistan. Maternal and child health journal, 19(9), pp.1993-2002.

131. Imdad, A. and Bhutta, Z.A., 2013. Nutritional management of the low birth weight/preterm infant in community settings: a perspective from the developing world. The Journal of pediatrics, 162(3), pp.S107-S114.

132. Lassi, Z.S., Haider, B.A. and Bhutta, Z.A., 2010. Community-based intervention packages for reducing maternal and neonatal morbidity and mortality and improving neonatal outcomes. Cochrane Database Syst Rev,11(11). http://onlinelibrary.wiley.com/doi/10.1002/14651858.CD007754.pub3/full

133. Linkages Among Reproductive Health, Maternal Health, and Perinatal Outcomes, Seminars in Perinatology, Volume 34, Issue 6, December 2010, Pages 434-445 Zulfiqar A. Bhutta, Zohra S. Lassi, Ann Blanc, France Donnay.http://www.sciencedirect.com/science/article/pii/S0146000510001023

134. Structured training in the management of emergencies in mothers, babies and children in a poorly resourced health system: Logbooks to document skill use, Resuscitation, Volume 80, Issue 4, April 2009, Pages 449-452, Shamsa Zafar, Assad Hafeez, Farrukh Qureshi, Naureen Arshad, David Southall. http://www.sciencedirect.com/science/article/pii/S030095720800837X

135. Privatisation in reproductive health services in Pakistan: three case studies, Reproductive Health Matters, Volume 18, Issue 36, November 2010, Pages 13-24, TK Sundari Ravindra. http://www.sciencedirect.com/science/article/pii/S0968808010365360?np=y 
136. Reducing maternal, newborn, and infant mortality globally: An integrated action agenda, International Journal of Gynecology \& Obstetrics, Volume 119, Supplement 1, October 2012, Pages S13-S17, Zulfiqar A. Bhutta, Sergio Cabral, Chok-wan Chan, William $J$ Keenan http://www.sciencedirect.com/science/article/pii/S0020729212001701

137. Interventions to address maternal, newborn, and child survival: what difference can integrated primary health care strategies make? The Lancet, Volume 372, Issue 9642, 13-19 September 2008, Pages 972-989 Zulfiqar A Bhutta, Samana Ali, Simon Cousens, Talaha M Ali, Batool Azra Haider, Arjumand Rizvi, Pius Okong, Shereen Z Bhutta, Robert E Black. http://www.sciencedirect.com/science/article/pii/S0140673608614075

138. Accessibility of antenatal services at primary healthcare facilities in Punjab, Pakistan, JPMA. Journal of the Pakistan Medical Association. 2013 Apr; 63(4 Suppl 3):S60-6,Majrooh MA; Hasnain S; Akram J; Siddiqui A; Shah F; Memon ZA. http://www.popline.org/node/578521

139. Hannan, A., Malik, M.A., Fasih, S., Badar, F. and Siddiqui, N., 2015. MALIGNANT OVARIAN GERM CELL TUMORS AT A TERTIARY CARE SETTING IN PAKISTAN. Journal of Ayub Medical College Abbottabad,27(3), pp.624-627.

140. Fatemeh, T., Marziyeh, G., Nayereh, G., Anahita, G. and Samira, T., 2010. Maternal and perinatal outcome in nulliparious women complicated with pregnancy hypertension. JPMA. The Journal of the Pakistan Medical Association, 60(9), p.707.

141. Saeed, F., Jawad, A., Azmat, A., Syed, I.A. and Kagazwala, S., 2011. Anthropometric measurements as a risk for hypertensive disorders in pregnancy: a hospital based study in South Asian population. Journal of the Pakistan Medical Association, 61(1), p.58.

142. Ali, A., Ali, M.A., Ali, M.U. and Mohammad, S., 2011. Hospital outcomes of obstetrical-related acute renal failure in a tertiary care teaching hospital.Renal failure, 33(3), pp.285-290.

143. Kisat, M., Fatimi, S.H., Sheikh, L. and Samad, K., 2011. Mitral valve replacement in a twin pregnancy. Journal of Obstetrics and Gynaecology Research, 37(7), pp.916918.

144. Kashif, W., Yaqub, S., Ahmed, H., Khan, N., Subhan, A. and Hussain, S.A., 2013. Successful pregnancy in a kidney transplant recipient with chronic hepatitis $B$ virus infection. Iranian journal of kidney diseases, 7(5), p.407.

145. Haroon, A., Ali, S.R., Ahmed, S. and Maheen, H., 2014. Short-Term Neonatal Outcome in Late Preterm vs. Term Infants. Journal of the College of Physicians and Surgeons Pakistan, 24(1), pp.34-38.

146. Muhammad, T., Khattak, A.A., Shafiq-ur-Rehman, K.M., Khan, A. and Khan, M.A., 2010. Maternal factors associated with intrauterine growth restriction. J Ayub Med Coll Abbottabad, 22(4), pp.64-69. 
147. Nawaz, F.H., Khalid, R., Naru, T. and Rizvi, J., 2009. Does Continuous Use of Metformin Throughout Pregnancy Improve Pregnancy Outcomes in Women With Polycystic Ovarian Syndrome?. Obstetrical \& Gynecological Survey, 64(2), pp.8889.

148. Afzal, E., Sherin, F. and Seema, N., 2015. CORELATION OF ADVERSE PERINATAL OUT COMES AND PLACENTAL INFARCTS IN HYPERTENSIVE PRETERM PREGNANCIES. Journal of Ayub Medical College Abbottabad, 27(3), pp.647-649.

149. Alpha-fucosidosis - Two brothers presenting with dysostosis multiplex, Egyptian Journal of Medical Human Genetics, 30 December 2015, Rimshah Shaukat, Syed Musa Raza, Zabedah Md. Yuns, Affandi Omar, Bushra Afroze http://www.sciencedirect.com/science/article/pii/S1110863015001238

150. A novel homozygous ISPD gene mutation causing phenotype variability in a consanguineous family, Neuromuscular Disorders, Volume 25, Issue 1, January 2015, Pages 55-59 Giovanni Baranello, Simona Saredi, Serena Sansanelli, Paolo Savadori, Eleonora Canioni, Luisa Chiapparini, Paolo Balestri, Alessandro Malandrini, Maria Teresa Arnoldi, Chiara Pantaleoni, Lucia Morandi, Marina Mora. http://www.sciencedirect.com/science/article/pii/S0960896614006361

151. Intimate partner violence and its association with women's reproductive health in Pakistan, International Journal of Gynecology \& Obstetrics, Volume 117, Issue 1, April 2012, Pages 10-14, Rubeena Zakar, Muhammad Z. Zakar, Rafael Mikolajczyk, Alexander Krämer. http://www.sciencedirect.com/science/article/pii/S0020729211006400

152. CLN6 disease caused by the same mutation originating in Pakistan has varying pathology, European Journal of Paediatric Neurology Volume 17, Issue 6, November 2013, Pages 657-660, Rita Guerreiro, Jose T. Bras, Mariana Vieira, Varun Warrier, Shakti Agrawal, Helen Stewart, Glenn Anderson, Sara E. Mole http://www.sciencedirect.com/science/article/pii/S1090379813000688

153. Saeed, M., Perwaiz lqbal, M., Yousuf, F.A., Perveen, S., Shafiq, M., Sajid, J. and Frossard, P.M., 2007. Interactions and associations of paraoxonase gene cluster polymorphisms with myocardial infarction in a Pakistani population. Clinical genetics, 71(3), pp.238-244.

154. Kumari, K., Seetlani, N.K. and Akhter, R., 2015. The emergent concern of seropositive status of hepatitis-b virus and hepatitis-c virus in the pregnant females attending a tertiary care hospital. J Ayub Med Coll Abbottabad,27(1), pp.155-7.

155. Wasay, M., Saadatnia, M., Venketasubramanian, N., Kaul, S., Menon, B., Gunaratne, P., Malik, A., Mehmood, K., Ahmed, S., Awan, S. and Mehndiratta, M.M., 2012. Predictors of cerebral venous thrombosis and arterial ischemic stroke in young Asian women. Journal of Stroke and Cerebrovascular Diseases, 21(8), pp.689-694. 
156. Shakoor, S., Ismail, H. and Munim, S., 2013. Intracardiac echogenic focus and fetal outcome-review of cases from a tertiary care centre in Karachi, Pakistan. The Journal of Maternal-Fetal \& Neonatal Medicine, 26(1), pp.2-4.

157. Salam, R.A., Das, J.K. and Bhutta, Z.A., 2014. Impact of intrauterine growth restriction on long-term health. Current Opinion in Clinical Nutrition \& Metabolic Care, 17(3), pp.249-254.

158. Memon, M.A., Aziz, W. and Abbas, F., 2014. Surgical management of pheochromocytoma in a 13-week pregnant woman. BMJ case reports, 2014, p.bcr2013202838.

159. Khealani, B.A., Wasay, M., Saadah, M., Sultana, E., Mustafa, S., Khan, F.S. and Kamal, A.K., 2008. Cerebral venous thrombosis A descriptive multicenter study of patients in Pakistan and Middle East. Stroke, 39(10), pp.2707-2711.

160. Kumari, K., Seetlani, N.K. and Akhter, R., 2015. The emergent concern of seropositive status of hepatitis-b virus and hepatitis-c virus in the pregnant females attending a tertiary care hospital. J Ayub Med Coll Abbottabad,27(1), pp.155-7.

161. Khan, E.A., Khan, R., Iqbal, M.T., Hasan, Q., Farrukh, S., Rana, M.S. and Khan, W.M., 2015. Risk characterization of maternal and neonatal tetanus in view of tetanus vaccination campaigns in pakistan. J Ayub Med Coll Abbottabad, 27(1), pp.220-2.

162. Yousuf, N., Shaikh, S.N., Soomro, A. and Baloch, R., 2015. Analysis of clinical characteristics, rationale, and management of critically ill obstetric patients transferred to ICU. JPMA. The Journal of the Pakistan Medical Association, 65(9), pp.959-962.

163. Qadir, M.I., Maqbool, F., Maqbool, A. and Ali, M., 2015. HIV-Plasmodium Coinfection: Malaria in AIDS patients. Pak. J. Pharm. Sci, 28(5), pp.1811-1817.

164. Jan, M.R., Nazli, R., Shah, J. and Akhtar, T., 2012. A study of lipoproteins in normal and pregnancy induced hypertensive women in tertiary care hospitals of the North West Frontier Province-Pakistan. Hypertension in pregnancy,31(2), pp.292-299.

165. Wasay, M., Kaul, S., Menon, B., Venketasubramanian, N., Gunaratne, P., Khalifa, A., Poungvarin, N., Saadatnia, M., Gan, R.N., Dai, A. and Mehndiratta, M.M., 2010. Ischemic stroke in young Asian women: risk factors, subtypes and outcome. Cerebrovascular Diseases, 30(4), pp.418-422.

166. Mazher, S.B. and Kanwal, S., 2010. Twin birth weight discordance: associated factors and outcome. J Coll Physicians Surg Pak, 20(6), pp.391-4.

167. Danish, N., Fawad, A. and Abbasi, N., 2010. Assessment of pregnancy outcome in Primigravida: Comparison between booked and un-booked patients. J Ayub Med Coll Abbottabad, 22(2), pp.23-5.

168. Jalil, F., Moore, S.E., Butt, N.S., Ashraf, R.N., Zaman, S., Prentice, A.M. and Hanson, L.A., 2008. Early-life Risk Factors for Adult Chronic Disease: Follow-up of a Cohort 
Born During 1964-1978 in an Urban Slum of Lahore, Pakistan. Journal of health, population, and nutrition, 26(1), p.12.

169. Mazhar, S.B., Rahim, F. and Furukh, T., 2008. Fetomaternal outcome in triplet pregnancy. J Coll Physicians Surg Pak, 18(4), pp.217-21.

170. Umber, A. and Chohan, M.A., 2007. Intravenous maternal hydration in third trimester oligohydramnios: effect on amniotic fluid volume. Journal of the College of Physicians and Surgeons--Pakistan: JCPSP, 17(6), pp.336-339.

171. Naqvi, R., Noor, H., Ambareen, S., Khan, H., Haider, A., Jafri, N., Alam, A., Aziz, R., Manzoor, K., Aziz, T. and Ahmed, E., 2006, September. Outcome of pregnancy in renal allograft recipients: SIUT experience. InTransplantation proceedings (Vol. 38, No. 7, pp. 2001-2002). Elsevier.

172. Rao, A.K., Daniels, K., El-Sayed, Y.Y., Moshesh, M.K. and Caughey, A.B., 2006. Perinatal outcomes among Asian American and Pacific islander women. American journal of obstetrics and gynecology, 195(3), pp.834-838.

173. http://www.ncbi.nlm.nih.gov/pubmed/5121777

174. Khowaja, A.R., Mitton, C., Bryan, S., Magee, L.A., Bhutta, Z.A. and von Dadelszen, P., 2015. Economic evaluation of Community Level Interventions for Pre-eclampsia (CLIP) in South Asian and African countries: a study protocol. Implementation Science, 10(1), p.76.

175. Mustafa, R. and Hashmi, H., 2009. Near-miss obstetrical events and maternal deaths. J Coll Physicians Surg Pak, 19(12), pp.781-5.

176. Ghazi, A., Ali, T., Jabbar, S., Siddiq, N.M., Lata, S., Noren, S. and Mansoor, M., 2009. Perinatal mortality contributors in singleton gestation.J Coll Physicians Surg Pak, 19(11), pp.711-713.

177. Salam, R.A., Zuberi, N.F. and Bhutta, Z.A., 2015. Pyridoxine (vitamin B6) supplementation during pregnancy or labour for maternal and neonatal outcomes. status and date: New search for studies and content updated (no change to conclusions), published in, (6).

178. Rizwan, N., Rauf, S. and Farhan-Uddin, S., 2013. Maternal and perinatal outcomes among women with eclampsia admitted to a tertiary care hospital in Hyderabad, Pakistan. International journal of gynaecology and obstetrics: the official organ of the International Federation of Gynaecology and Obstetrics, 123(3), pp.247-248.

179. West, J., Lawlor, D.A., Fairley, L., Bhopal, R., Cameron, N., McKinney, P.A., Sattar, N. and Wright, J., 2013. UK-born Pakistani-origin infants are relatively more adipose than white British infants: findings from 8704 mother-offspring pairs in the Born-inBradford prospective birth cohort. Journal of epidemiology and community health, pp.jech-2012. 
180. Mohammed, N.B. and Kakal, F., 2008. Uterine artery Doppler ultrasonography in the first and second trimester for prediction of preeclampsia: implications for Pakistan. JPMA. The Journal of the Pakistan Medical Association, 58(12), p.718.

181. Rohra, D.K., Khan, N.B., Azam, S.I., Sikandar, R., Zuberi, H.S., Zeb, A., Qureishi, R.N. and Hasan, R., 2009. Reasons of refusal and drop out in a follow up study involving primigravidae in Pakistan. Acta obstetricia et gynecologica Scandinavica, 88(2), pp.178-182.

182. Mahmud, G., Javaid, K., Tasnim, N., Tabassum, A. and Bangash, K.T., 2014. Where does ergometrine stand in prevention of postpartum haemorrhage in caesarean section?. JPMA. The Journal of the Pakistan Medical Association, 64(8), pp.911914.

183. Hossain, N., Khanani, R., Hussain-Kanani, F., Shah, T., Arif, S. and Pal, L., 2011. High prevalence of vitamin D deficiency in Pakistani mothers and their newborns. International Journal of Gynecology \& Obstetrics, 112(3), pp.229-233.

184. Bukhari, S.A., Rajoka, M.I., Ibrahim, Z., Jalal, F., Rana, S.M. and Nagra, S.A., 2011. Oxidative stress elevated DNA damage and homocysteine level in normal pregnant women in a segment of Pakistani population. Molecular biology reports, 38(4), pp.2703-2710.

185. Ishaq, S., Khalil, S., Khan, A. and Khalid, U., 2010. Chorea as an unusual presenting feature of anti-phospholipid syndrome. JPMA. The Journal of the Pakistan Medical Association, 60(11), pp.975-976.

186. Qazi, A., Ahmed, A.N., Qazi, M.P., Usman, F. and Ahmad, A., 2008. Ischaemic stroke with ovarian hyperstimulation syndrome. JPMA. The Journal of the Pakistan Medical Association, 58(7), pp.411-413.

187. Naru, T., Khurshid, M. and Nazir, Z., 2006. Maternal and fetal complications of antiphospholipid syndrome: a case report with long-term follow-up. JPMA. The Journal of the Pakistan Medical Association, 56(2), pp.84-86.

188. Hossain, N., Schatz, F. and Paidas, M.J., 2009. Heparin and maternal fetal interface: Why should it work to prevent pregnancy complications?.Thrombosis research, 124(6), pp.653-655.

189. Haider, B.A. and Bhutta, Z.A., 2006. Multiple-micronutrient supplementation for women during pregnancy. Cochrane Database Syst Rev, 4(4).

190. http://www.ncbi.nlm.nih.gov/pubmed/23472430

191. Pasha, O., Goldenberg, R.L., McClure, E.M., Saleem, S., Goudar, S.S., Althabe, F., Patel, A., Esamai, F., Garces, A., Chomba, E. and Mazariegos, M., 2010. Communities, birth attendants and health facilities: a continuum of emergency maternal and newborn care (the Global Network's EmONC trial).BMC pregnancy and childbirth, 10(1), p.82. 
192. Zafar, S., Hafeez, A., Qureshi, F., Arshad, N. and Southall, D., 2009. Structured training in the management of emergencies in mothers, babies and children in a poorly resourced health system: logbooks to document skill use. Resuscitation, 80(4), pp.449-452.

193. Brohi, Z.P., Sadaf, A. and Perveen, U., 2013. Etiology, clinical features and outcome of fulminant hepatic failure in pregnancy. Age (years), 29(8.404), pp.17-42.

194. Salam, R.A., Zuberi, N.F. and Bhutta, Z.A., 2015. Pyridoxine (vitamin B6) supplementation during pregnancy or labour for maternal and neonatal outcomes. status and date: New search for studies and content updated (no change to conclusions), published in, (6). http://onlinelibrary.wiley.com/doi/10.1002/14651858.CD000179.pub3/full

195. Haider, B.A. and Bhutta, Z.A., 2006. Multiple-micronutrient supplementation for women during pregnancy. Cochrane Database Syst Rev, 4(4). http://onlinelibrary.wiley.com/doi/10.1002/14651858.CD004905.pub4/full

196. Kamal, A.K., Naqvi, I., Husain, M.R. and Khealani, B.A., 2011. Cilostazol versus aspirin for secondary prevention of vascular events after stroke of arterial origin. Stroke, 42(6), pp.e382-e384. http://onlinelibrary.wiley.com/doi/10.1002/14651858.CD008076.pub2/full

197. Lassi, Z.S., Salam, R.A., Haider, B.A. and Bhutta, Z.A., 2013. Folic acid supplementation during pregnancy for maternal health and pregnancy outcomes. Cochrane Database Syst Rev, 3. http://onlinelibrary.wiley.com/doi/10.1002/14651858.CD006896.pub2/full

198. Lassi, Z.S. and Bhutta, Z.A., 2012. Mid-level health workers for improving the delivery of health services. The Cochrane Library. http://onlinelibrary.wiley.com/doi/10.1002/14651858.CD009649/full

199. Haider, B.A., Humayun, Q. and Bhutta, Z.A., 2009. Effect of administration of antihelminthics for soil transmitted helminths during pregnancy. Cochrane Database Syst Rev, 2. http://onlinelibrary.wiley.com/doi/10.1002/14651858.CD005547.pub3/full

200. Mumtaz, K., Ahmed, U.S., Zuberi, N.F., Salamat, S. and Jafri, W., 2010. Lamivudine during pregnancy for preventing hepatitis $B$ virus infection in newborns. The Cochrane Library. http://onlinelibrary.wiley.com/doi/10.1002/14651858.CD008718/full

201. Gazi, R., Hossain, S.S., Zaman, K. and Koehlmoos, T.P., 2011. Community mobilization for safe motherhood. The Cochrane Library. http://onlinelibrary.wiley.com/doi/10.1002/14651858.CD009091/full

202. Farooq, S. and Sherin, A., 2008. Interventions for psychotic symptoms concomitant with epilepsy. Cochrane Database Syst Rev, 4. http://onlinelibrary.wiley.com/doi/10.1002/14651858.CD006118.pub3/full 
203. Frequency, Pattern and Management of Acute Abdomen in Dengue Fever in Karachi, Pakistan,, ASIAN JOURNAL OF SURGERY VOL 33, NO 3, JULY 2010, Muhammad Shamim. http://www.sciencedirect.com/science/article/pii/S101595841060019X

204. A complex microcephaly syndrome in a Pakistani family associated with a novel missense mutation in RBBP8 and a heterozygous deletion in NRXN1, Gene, Volume 538, Issue 1, 15 March 2014, Pages 30-35, Zehra Agha, Zafar Iqbal, Maleeha Azam, Maimoona Siddique, Marjolein H. Willemsen, Tjitske Kleefstra, Christiane Zweier, Nicole de Leeuw, Raheel Qamar, Hans van Bokhoven http://www.sciencedirect.com/science/article/pii/S0378111914000481

205. A panoramic view on phytochemical, nutritional, ethanobotanical uses and pharmacological values of Trachyspermum ammi Linn, Asian Pacific Journal of Tropical Biomedicine, Volume 4, Supplement 2, July 2014, Pages S545-S553, Hafiz Muhammad Asif, Sabira Sultana, Naveed http://www.sciencedirect.com/science/article/pii/S2221169115300447

206. Chapter 23 - Betel Nut (Areca catechu) Usage and Its Effects on Health, Nuts and Seeds in Health and Disease Prevention, 2011, Niloufer Sultan Ali, Ali Khan Khuwaja.

http://www.sciencedirect.com/science/article/pii/B9780123756886100234

207. Neutron activation analysis of essential elements in Multani mitti clay using miniature neutron source reactor, Applied Radiation and Isotopes, Volume 70, Issue 10, October 2012, S. Waheed, S. Rahman, Y. Faiz, N. Siddique. http://www.sciencedirect.com/science/article/pii/S0969804312003958

208. Community-Acquired Acute Kidney Injury in Asia, Seminars in Nephrology, Volume 28, Issue 4, July 2008, Pages 330-347 Vivekanand Jha, Kirpal Chugh. http://www.sciencedirect.com/science/article/pii/S0270929508000806

209. Biallelic Truncating Mutations in FMN2, Encoding the Actin-Regulatory Protein Formin 2, Cause Nonsyndromic Autosomal-Recessive Intellectual Disability, The American Journal of Human Genetics, Volume 95, Issue 6, 4 December 2014, Pages 721-728, Rosalind Law, Tracy Dixon-Salazar, Julie Jerber. http://www.sciencedirect.com/science/article/pii/S0002929714004649

210. The first case of CDK5RAP2-related primary microcephaly in a non-consanguineous patient identified by next generation sequencing, Brain and Development, Volume 36, Issue 4, April 2014, Pages 351-355, Christopher A. Tan, Scott Topper, Catherine Ward Melver, Jennifer Stein, Amanda Reeder, Kelly Arndt, Soma Das. http://www.sciencedirect.com/science/article/pii/S0387760413001642

211. Hypomorphic Mutations in PGAP2, Encoding a GPI-Anchor-Remodeling Protein, Cause Autosomal-Recessive Intellectual Disability, The American Journal of Human Genetics, Volume 92, Issue 4, 4 April 2013, Pages 575-583, Lars Hansen, Hasan Tawamie, Yoshiko Murakami, Yuan Mang, Shoaib ur Rehman, ebecca Buchert, Stefanie Schaffer, Safia Muhammad, Mads Bak, Markus M. Nöthen, Eric P. Bennett, 
Yusuke Maeda, Michael Aigner, André Reis, Taroh Kinoshita, Niels Tommerup, Shahid Mahmood Baig, Rami Abou Jamra

212. Indigenous knowledge of folk medicines among tribal minorities in Khyber Pakhtunkhwa, northwestern

Pakistan, Journal of Ethnopharmacology, Volume 166, 26 May 2015, Pages 157-167 Hassan Sher, Ali Aldosari, Ahmad Ali, Hugo J. de Boer, http://www.sciencedirect.com/science/article/pii/S037887411500166X

213. Surgical management of valvular heart diseases in pregnancy, European Journal of Obstetrics \& Gynecology and Reproductive Biology, Volume 159, Issue 1, November 2011, Pages 91-94, Asif Jafferani, Ayesha Malik, Ranish Deedar Ali Khawaja, Lumaan Sheikh, Hasanat Sharif. http://www.sciencedirect.com/science/article/pii/S0301211511004532

214. Method of delivery and pregnancy outcomes in Asia: the WHO global survey on maternal and perinatal health 2007-08, The Lancet, Volume 375, Issue 9713, 6 12 February 2010, Pages 490-499, Pisake Lumbiganon, Malinee Laopaiboon, A Metin Gülmezoglu, João Paulo Souza, Surasak Taneepanichskul, Pang Ruyan, Deepika Eranjanie Attygalle, Naveen Shrestha, Rintaro Mori, Nguyen Duc Hinh, Hoang Thi Bang, Tung Rathavy, Kang Chuyun, Kannitha Cheang, Mario Festin, Venus Udomprasertgul, Maria Julieta V Germar, Gao Yanqiu, Malabika Roy, Guillermo Carroli, Katherine Ba-Thike, et al. http://www.sciencedirect.com/science/article/pii/S0140673609618705

215. Association of the leptin receptor GIn223 Arg polymorphism with lipid profile in obese Pakistani subjects, Nutrition, Volume 31, Issue 9, September 2015, Pages 1136-1140, N.A. Shabana, Shahida Hasnain. http://www.sciencedirect.com/science/article/pii/S0899900715002166

216. Evaluation of iodine, iron, and selenium in biological samples of thyroid mother and their newly born babies, Early Human Development, Volume 86, Issue 10, October 2010, Pages 649-655, Tasneem Gul Kazi, Ghulam Abbas Kandhro, Sirajuddin, Hassan Imran Afridi, Jameel Ahmed Baig, Abdul Qadir Shah, Sham Kumar Wadhwa, Sumaira Khan, Nida Fatima Kolachi, Hafeez-ur-Rahman Shaikh. http://www.sciencedirect.com/science/article/pii/S0378378210001830

217. Evidence-based interventions for improvement of maternal and child nutrition: what can be done and at what cost? The Lancet, Volume 382, Issue 9890, 3-9 August 2013, Pages 452-477, Zulfiqar A Bhutta, Jai K Das, Arjumand Rizvi, Michelle F Gaffey, Neff Walker, Susan Horton, Patrick Webb, Anna Lartey, Robert E Black, The Lancet. http://www.sciencedirect.com/science/article/pii/S0140673613609964

218. Postnatal growth standards for preterm infants: the Preterm Postnatal Follow-up Study of the INTERGROWTH-21st Project, The Lancet Global Health, Volume 3, Issue 11, November 2015, Pages e681-e691 José Villar, Francesca Giuliani, Zulfiqar A Bhutta, Enrico Bertino, Eric O Ohuma, Leila Cheikh Ismail, Fernando C Barros, Douglas G Altman, Cesar Victora, Julia A Noble, Michael G Gravett, Manorama Purwar, Ruyan Pang, Ann Lambert, Aris T Papageorghiou, Roseline Ochieng, Yasmin A Jaffer, Stephen H Kennedy, 
International Fetal and Newborn Growth Consortium for the 21 Century (INTERGROWTH-21)

http://www.sciencedirect.com/science/article/pii/S2214109X15001631

219. Effectiveness, safety and acceptability of Sino-implant (II) during the first year of use: results from Kenya and Pakistan, Contraception, Volume 89, Issue 3, March 2014, Pages 197-203, Anja Lendvay, Rose Otieno-Masaba, Syed Khurram Azmat, Angie Wheeless, Waqas Hameed, Babar Tasneem Shaikh, Shiphrah Kuria, Markus J. Steiner, Mario Chen, Paul J. Feldblum. http://www.sciencedirect.com/science/article/pii/S0010782413006896

220. Umbilical vein oxytocin for the treatment of retained placenta (Release Study): a double-blind, randomised controlled trial, The Lancet, Volume 375, Issue 9709, 9-15 January 2010, Pages 141-147 Andrew D Weeks, Godfrey Alia, Gillian Vernon, Annette Namayanja, Radhika Gosakan, Tayyaba Majeed, Anna Hart, Hussain Jafri, Juan Nardin, Guillermo Carroli, Fiona Fairlie, Yasmin Raashid, Florence Mirembe, Zarko Alfirevic. http://www.sciencedirect.com/science/article/pii/S0140673609617529

221. Intimate partner violence and its association with women's reproductive health in Pakistan, International Journal of Gynecology \& Obstetrics, Volume 117, Issue 1, April 2012, Pages 10-14, Rubeena Zakar, Muhammad Z. Zakar, Rafael Mikolajczyk, Alexander Krämer. http://www.sciencedirect.com/science/article/pii/S0020729211006400

222. Rate and indications of elective and emergency caesarean section; a study in a tertiary care hospital of Peshawar. Journal of Ayub Medical College, Abbottabad. 2015 Jan-Mar;

27(1):151-4 Naeem M; Khan MZ; Abbas SH; Khan A; Adil M; Khan MU. http://www.popline.org/node/638957

223. Maternal mortality in rural community: a challenge for achieving millennium development goal. Journal of Pakistan Medical Association. 2010 Jan; 60(1):20-24, Nisar N; Sohoo NA. http://www.popline.org/node/208734

224. Anaesthesia for caesarean section in patients with cardiac disease, JPMA. Journal of the Pakistan Medical Association. 2006 Jan; 56(1):32-38, Chohan U; Afshan G; Mone A. http://www.popline.org/node/167900

225. Screening of pregnant women for gestational diabetes mellitus, JAMC. Journal of Ayub Medical College, Abbottabad. 2005 Apr-Jun; 17(2):5458,Hassan A. http://www.popline.org/node/255975

226. Fetomaternal outcome in pregnancy with cardiac disease, Journal of the College of Physicians and Surgeons, Pakistan. 2005; 15(8):476-480, Gul-e-Irum; Mazhar SB. http://www.popline.org/node/255273

227. Periodontal infection: a potential risk factor for pre-term delivery of low birth weight (PLBW) babies, JPMA. Journal of the Pakistan Medical Association. 2005 Oct; 
55(10):[9] p.., Qureshi A; ljaz S; Syed A; Qureshi A. http://www.popline.org/node/256798

228. Maternal mortality in a tertiary care hospital. Journal of Ayub Medical College, Abbottabad. 2011 Jan-Mar; 23(1):92-5,Fawad A; Naz H; Islam A; Zaffar S; Abbasi AU. http://www.popline.org/node/574739

229. Severe acute maternal morbidity (SAMM) in postpartum period requiring tertiary hospital care, Iranian Journal of Reproductive Medicine. 2012 Mar; 10(2):8792,Bibi S; Ghaffar S; Memon S; Memon S. http://www.popline.org/node/536258

230. Frequency of eclampsia and maternal complications in a tertiary care facility of Peshawar,

Pakistan Journal of Medical Research. 2008 Oct-Dec; 47(4):79-82,Ahmad S; Nazli R; Lutfullah G. http://www.popline.org/node/205312

231. Screening of pregnant women for gestational diabetes mellitus, JAMC. Journal of Ayub Medical College, Abbottabad. 2005 Apr-Jun; 17(2):5458,Hassan A. http://www.popline.org/node/255975

232. Frequency of thrombophilia in patients with adverse pregnancy outcome, JPMA. Journal of the Pakistan Medical Association. 2005 Jun; 55(6):245-247, Hossain N; Shamsi T; Soomro N. http://www.popline.org/node/255293

233. Severe acute maternal morbidity (SAMM) in postpartum period requiring tertiary hospital care, Iranian Journal of Reproductive Medicine. 2012 Mar; 10(2):87-92, Bibi S; Ghaffar S; Memon S; Memon S. http://www.popline.org/node/536258

234. High prevalence of vitamin D deficiency in Pakistani mothers and their newborns., International Journal of Gynaecology and Obstetrics. 2011 Mar; 112(3):229-33, Hossain N; Khanani R; Hussain-Kanani F; Shah T; Arif S; Pal L, http://www.popline.org/node/221355

235. Ahmed, I., Atiq, M., Iqbal, J., Khurshid, M. and Whittaker, P., 1995. Vitamin D deficiency rickets in breast-fed infants presenting with hypocalcaemic seizures. Acta paediatrica, 84(8), pp.941-942.

236. Atiq, M., Suria, A., Nizami, S.Q. and Ahmed, I., 1998. Vitamin D status of breastfed Pakistani infants. Acta Pædiatrica, 87(7), pp.737-740.

237. Imdad, A. and Bhutta, Z.A., 2012. Effects of calcium supplementation during pregnancy on maternal, fetal and birth outcomes. Paediatric and perinatal epidemiology, 26(s1), pp.138-152

238. Naqvi, S.A.A., Rizvi, S.A.H., Zafar, M.N., Ahmed, E., Ali, B., Mehmood, K., Awan, M.J., Mubarak, B. and Mazhar, F., 2008. Health status and renal function evaluation of kidney vendors: a report from Pakistan. American Journal of Transplantation, 8(7), pp.1444-1450. 
239. Lassi, Z.S., Salam, R.A., Haider, B.A. and Bhutta, Z.A., 2013. Folic acid supplementation during pregnancy for maternal health and pregnancy outcomes. Cochrane Database Syst Rev, 3.

240. Akbar, S.A., Khawaja, N.P., Brown, P.R., Tayyeb, R., Bamfo, J. and Nicolaides, K.H., 2009. Angiotensin II type 1 and 2 receptors gene polymorphisms in pre-eclampsia and normal pregnancy in three different populations. Acta obstetricia et gynecologica Scandinavica, 88(5), pp.606-611.

241. Saleem, F., Hassali, M.A. and Shafie, A.A., 2014. A cross-sectional assessment of health-related quality of life (HRQoL) among hypertensive patients in Pakistan. Health Expectations, 17(3), pp.388-395.

242. Khan, M., Hashmani, F.N., Ahmed, S., Ahmed, O., Asim, S.S., Wajahat, Y., Sobani, S., Syed, S. and Qazi, F., 2015. Prospective cohort study of a new vacuum delivery device to assist with complicated labour in low-resource settings. Tropical Medicine \& International Health, 20(2), pp.219-226.

243. Shah, S.M., Nanan, D., Rahbar, M.H., Rahim, M. and Nowshad, G., 2004. Assessing obesity and overweight in a high mountain Pakistani population.Tropical Medicine \& International Health, 9(4), pp.526-532.

244. Qureshi, I.A., 1996. Ocular hypertensive effect of menopause with and without systemic hypertension. Acta obstetricia et gynecologica Scandinavica, 75(3), pp.266-269.

245. Borhany, M., Handrkova, H., Cairo, A., Schroeder, V., Fatima, N., Naz, A., Amanat, S., Shamsi, T., Peyvandi, F. and Kohler, H.P., 2014. Congenital factor XIII deficiency in Pakistan: characterization of seven families and identification of four novel mutations. Haemophilia, 20(4), pp.568-574.

246. Lindblad, B.S., RAHIMTOOLA, R.J., SAID, M., HAQUE, Q. and KHAN, N., 1969. THE VENOUS PLASMA FREE AMINO ACID LEVELS OF MOTHER AND CHILD DURING DELIVERY. III. Acta Paediatrica, 58(5), pp.497-505.

247. Saleem, F., Hassali, M.A. and Shafie, A.A., 2014. A cross-sectional assessment of health-related quality of life (HRQoL) among hypertensive patients in Pakistan. Health Expectations, 17(3), pp.388-395.

248. Ali, N., Bhatti, F.A. and Khan, S.A., 2014. Frequency of hereditary thrombophilia in women with recurrent pregnancy loss in Northern Pakistan.Journal of Obstetrics and Gynaecology Research, 40(6), pp.1561-1566.

249. Hussain, R., 1998. The impact of consanguinity and inbreeding on perinatal mortality in Karachi, Pakistan. Paediatric and perinatal epidemiology, 12(4), pp.370-82. 
46 (C) 2016 The Population Council, Inc. 